\title{
Mechanisms of Maternal Immune Tolerance During Pregnancy
}

\author{
John E. Schjenken ${ }^{1}$, Jorge M. Tolosa ${ }^{1,2}$, \\ Jonathan W. Paul ${ }^{1}$, Vicki L. Clifton ${ }^{3}$ and Roger Smith ${ }^{1}$ \\ ${ }^{1}$ Mothers and Babies Research Centre, University of Newcastle, \\ New Lambton Heights, NSW, \\ ${ }^{2}$ Faculty of Medical Sciences, University of Santiago of Chile, Santiago, \\ ${ }^{3}$ Robinson Institute, Lyell McEwin Hospital, Elizabeth Vale, SA \\ ${ }_{1,3}$ Australia \\ ${ }^{2}$ Chile
}

\section{Introduction}

Throughout their evolution, animals have developed mechanisms which protect them against parasites or infections by detecting and destroying foreign biological material within their own bodies. These mechanisms for excluding "non-self" biological materials whilst at the same time maintaining the integrity of the "self" have evolved for hundreds of millions of years into a highly complex body system, the immune system (Bainbridge, 2000). Any disbalance or alteration of the mechanisms maintaining the dynamic equilibrium between the "self" and "non-self" recognition could translate into a pathological state (or condition) like autoimmune disease at one end of the scale or immunodeficiency at the other.

The immunological system in placental mammals has been particularly challenged throughout the course of evolution, not just because of the exposure to a wide range of pathogens ("non-self") but because the evolution of the placenta allowed females to maintain fetuses within the reproductive tract for prolonged periods. One of the most intriguing features of mammalian embryo development is the re-organization of the maternal uterine tissue (endometrium) by embryo derived cells (trophoblast cells) in order to establish an intimate association with the mother. This process starts with embryo implantation and is characterized by the invasion of uterine tissues by the embryonic cells (trophoblast cells), culminating with the formation of the placenta, which permits intrauterine nourishment of the fetus, removal of waste metabolites, and the exchange of respiratory gasses to and from the fetal circulation until the moment of birth.

The intimate association between mother and embryo in placental mammals creates the potential problem of two genetically distinct individuals having to coexist for the duration of the pregnancy. This means that during pregnancy, the mothers' immune system has to tolerate the presence of paternal alloantigens ("nonself") from the placenta and/or the fetus (Bainbridge, 2000). In this context, pregnancy is a unique immunological challenge and it has been compared to the transplantation of a tissue or organ from a donor that is tolerated by the recipient (mother) and not rejected. 
The paradox of the fetal allograft (transplant), as this process has been called, has been the dominant hypothesis driving research and debate in the field of reproductive immunology and the question why the mother does not reject the feto-placental unit remains unanswered. No other tissue, when surgically transplanted between genetically different individuals, enjoys the impunity from lethal host immune responses that characterizes the maternal-fetal relationship.

More than 50 years have passed since Peter Medawar (Medawar, 1953) made one of the most influential contributions to the field of Reproductive Immunology with his essay entitled "Some Immunological and Endocrinological Problems Raised by the Evolution of Viviparity in Vertebrates". Based on his pioneering studies demonstrating the role of tissue antigens in the recognition and rejection of skin grafts between genetically different individuals, and the work of others (reviewed in (Billington, 2003)) on the genetic basis of tumor transplant rejection in mice, Medawar recognized the truly paradoxical nature of the immunological relationship between the mother and her fetus. In his words: "The immunological problem of pregnancy may be formulated thus: How does the pregnant mother contrive to nourish within itself, for many weeks or months, a fetus that is an antigenically foreign body?" (Medawar, 1953).

This immunological paradox exists because according to the laws of tissue transplantation, fetal alloantigens encoded by polymorphic genes inherited from the father should provoke maternal immune responses leading to fetal rejection soon after blastocyst implantation in the uterine wall (Billingham, 1964; Medawar, 1953). From a genetic perspective, mother and fetus are never identical in outbred populations because the fetus inherits a different set of polymorphic genes from each parent and multiple tissue antigens differ between fetus and mother. Even more extraordinary is the case of surrogate mothers, where the feto-placental unit represents a bigger alloantigen challenge for the mother and can be considered a perfect example of a successful allotransplantation (at least temporarily).

Originally, Medawar proposed three explanations to answer the question as to how the fetus does not usually provoke an immunological reaction from its mother: (1) the anatomical separation of fetus from mother; (2) the antigenic immaturity of the fetus; and (3) the immunological indolence or inertness of the mother" (Medawar, 1953).

Medawar himself was convinced that the anatomical separation of fetus from mother, by a barrier considered at that time to be impermeable to maternal cells, was by far the most important of these possible explanations. Very early on, Billingham (Billingham, 1964) drew attention to the growing evidence for bi-directional transfer of cellular elements between mother and fetus, indicating that the placenta cannot be regarded as an absolute barrier. It is now known that in species with hemochorial placentation, as in humans and rodents, the mother and the fetus are not separated by an intact layer of epithelial cells, and placental trophoblast cells are thus exposed to maternal immune cells. A bidirectional transfer of cells between mother and fetus is common during human and murine pregnancy, and can lead to microchimerism (Nelson et al., 2007).

The second hypothesis proposed by Medawar, that the conceptus lacked immunogenicity, has been shown in studies by Hoskin and others (Elbe-Burger et al., 2000; Hoskin and Murgita, 1989) not to occur as immune reactions against fetal cells have been described. Hoskin and Murgita (Hoskin and Murgita, 1989) showed an immune reaction against fetal 
cells in the mouse. In this study, splenic T cells with a helper phenotype obtained from primiparous $\mathrm{CBA} / \mathrm{J}$ mice pregnant by syngeneic matings were found to proliferate in response to co-culture with fetal thymus cells. Maternal anti-fetal lymphoproliferative responses were also shown to be blocked by the addition of antibodies against major histocompatibility complex (MHC) molecules (Hoskin and Murgita, 1989). More recently, studies have shown that fetal tissue expresses MHC molecules which are required for immune recognition and activation (reviewed in (Bainbridge, 2000)). All together, these data showed that the conceptus had immunogenic properties.

In reference to Medawar's third hypothesis, there is ample evidence that pregnancy is recognized by the immune system. Antibodies against fetal antigens have been detected in the sera of pregnant women showing that maternal recognition of fetal antigens does occur (reviewed in (Billington, 1992)). Women undergoing normal pregnancy preferentially release type 2 helper $\mathrm{T}$ cell (Th2) cytokines, whereas women who have recurrent spontaneous abortions induce the production of type 1 helper $\mathrm{T}$ cell (Th1) cytokines (Raghupathy, 1997). Thus the maternal immune system not only recognizes pregnancy but responds in a way which can determine the success or failure of pregnancy.

The maternal immune system is clearly active, and under certain conditions may contribute to fetal damage/death. Well-defined pathological processes include destruction of fetal erythrocytes (Rh antigen, erythroblastosis) and platelets (HPA-1 and -2, alloimmune thrombocytopenia) by maternal antibodies and infections of pregnancy, where activated macrophages secreting high levels of Th1-type cytokines alter the delicate cytokine balance at the maternal-fetal interface (Hunt, 1989; Marzi et al., 1996). Yet even with a demonstrably active maternal immune system, mothers usually seem to tolerate rather than reject their genetically disparate fetuses (Hunt et al., 2005). Because of this, it has been necessary to reconsider the physiological interactions and physical contacts between fetal and maternal elements as a dynamic entity occurring at different levels during the course of pregnancy.

Following on from Medawar's original hypotheses, a fourth conceptual proposal was advanced by Billingham in 1964 (Billingham, 1964). Billingham proposed that the uterus may be an immune privileged site, where fetal tissue directs the maternal immune response towards a protective, tolerant one. The concept of immune-privileged sites has been recognized by immunologists for nearly 135 years, since the Dutch ophthalmologist Van Dooremaal observed prolonged survival of a mouse skin graft placed into the anterior chamber of a dog's eye (reviewed in (Stein-Streilein and Streilein, 2002)). Together with the anterior chamber of the eye, other tissues such brain, ovary, testis, pregnant uterus, and placenta, display many of the characteristics of immune-privileged sites where immune reactions are not initiated in response to tissues displaying histocompatibility differences either by setting up anatomical and/or physiological barriers, which prevent access to cells of the immune system (Trowsdale and Betz, 2006).

Experimental studies have since shown that transplant immunity can be both elicited and expressed in a normal manner in the uterus. This was shown initially by Poppa et al., in 1964, who demonstrated the rejection of intrauterine parathyroid allografts in pseudopregnant parathyroidectomized rats (Poppa et al., 1964). Also, the possibility of ectopic pregnancies demonstrates that the uterus does not uniquely protect the conceptus as an immune privileged site (Billington, 2003). 
So the question is how does the mother's immune system recognize and respond to fetoplacental antigens in a way that promotes successful pregnancy and not immune rejection? It is known from extensive studies in transplantation that a semi-allogeneic graft will be promptly rejected without adequate pharmacological control of the recipient's immune system, whereas the semi-allogeneic fetus which expresses antigens derived from both the mother and the father can survive throughout normal pregnancy without immunological rejection (Billington, 2003). This suggests that the developing fetus has mechanisms which prevent a maternal immune response against paternal/fetal antigens. Indeed, studies have shown that during pregnancy, paternal alloantigens can avoid maternal immune rejection. Tafuri et al., showed that female mice would accept an allogeneic tumor graft while pregnant with a conceptus from a father matching the allograft but if the tumor cells were transplanted from a third party allogeneic donor, they would be rejected. Further, after the delivery of the mice, paternal tumors would be rejected showing that this tolerance only occurred during pregnancy (Tafuri et al., 1995).

The immune regulatory processes operating at the level of the maternal-fetal interface are highly dynamic and invoke multiple and sometimes redundant mechanisms and/or factors to reduce the likelihood of maternal immune rejection. Together with this redundancy, it is widely accepted that fetal factors drive changes in maternal immune responses and that both the fetus and the mother actively contribute to the development and maintenance of the pregnant uterus as an immune privileged site.

To understand the physiological mechanisms of maternal immune tolerance of the semiallogeneic fetus during pregnancy has relevant implications not just for the field of Reproductive Immunology but also is clinically relevant for immune-mediated diseases (e.g., autoimmunity and asthma/allergy), cancer and for cell and organ transplantation. While the precise cellular interactions and mechanisms involved in maternal tolerance to the semi-allograft feto-placental unit are not yet completely understood, the identity of some of the critical factors and mechanisms have been uncovered and some details follow.

\section{Mechanisms of maternal immune tolerance}

\subsection{Complement system}

The innate branch of the immune system comprises the cells and mechanisms that defend the host from foreign organisms in a non-specific manner. Central to innate immune responses is the complement system (Girardi, 2008). Over 30 proteins are involved in its activation and they act in concert to protect the host against invading organisms (Girardi, 2008; Girardi et al., 2006). Activation of the complement cascade promotes chemotaxis of inflammatory cells and osmotic lysis of mammalian and bacterial cells through the formation of membrane attack complexes and is commonly used by the immune system to kill foreign or cancerous cells (Danilova, 2006). The complement cascade is regulated by complement regulatory proteins (CRP) that are expressed on cells and are critical for protecting tissues from inflammation that occurs in response to complement activation.

The complement cascade can be activated by three different pathways: the classical, the mannose binding lectin, and the alternative pathway. These pathways are activated as a result of different stimuli. The classical pathway is triggered by the presence of antibody 
bound to a target antigen, the lectin pathway is initiated by carbohydrates on microbial surfaces and the alternative pathway is spontaneously and constantly activated on biological surfaces in plasma and in most other body fluids allowing for rapid complement activation in response to foreign antigens (Zipfel and Skerka, 2009). These three activation pathways lead to the cleavage of the $\mathrm{C} 3$ component and the generation of $\mathrm{C} 3 \mathrm{a}$ and $\mathrm{C} 3 \mathrm{~b}$ fragments. $\mathrm{C} 3 \mathrm{a}$ causes the activation and release of inflammatory mediators such as histamine while $\mathrm{C} 3 \mathrm{~b}$ activates additional members of the complement cascade until the binding of $\mathrm{C} 5 \mathrm{~b}$ initiates the recruitment of the membrane attack complex (MAC). The MAC is a pore forming lipophilic complex that activates cell lysis, which results in permeabilization of the cell membrane and ultimately, cell death (Girardi, 2008; Zipfel and Skerka, 2009).

In transplantation, the activation of complement has been shown to be involved in acute graft rejections. The use of monoclonal antibodies to complement proteins has demonstrated that complement is activated and deposited on the vascular endothelium of the transplanted tissue in a significant number of acute rejections (Wasowska et al., 2007). However, complement can be regulated and the process of regulation can be controlled by the stimulation or inhibition of complement activation. Due to the similarities between pregnancy and tissue or organ transplantation, it has been suggested that appropriate complement inhibition is a requirement for successful pregnancy (Girardi, 2008). Indeed, as complement may be one of the components in the maternal blood which may damage trophoblast cells after its activation by antibodies, trophoblast cells have protective mechanisms which allow them to avoid complement activation. The placenta expresses three CRP: decay-accelerating factor (DAF), membrane co-factor protein (MCP), and CD59 (Tedesco et al., 1993). These regulatory proteins inhibit complement at different stages of the activation sequence. DAF and MCP both act early in the complement cascade to control C3 activation whilst CD59 is an inhibitor of the MAC (Morgan and Holmes, 2000). Thus, the expression of $\mathrm{CRP}$ at the maternal/fetal interface is a critical adaptation for protecting the fetus from injury inflicted by inflammation provoked by complement activation (Holmes et al., 1992).

The role of CRP in trophoblast complement inhibition is further supported in studies by Tedesco et al., 1993 (Tedesco et al., 1993), who tested the role of CRP in the vulnerability of human trophoblast to complement activation. In these studies the inhibition of MCP and CD59 resulted in an increased susceptibility of trophoblast cells to complement mediated immunological activation suggesting the inhibition of complement by MCP and CD59 is required for pregnancy to proceed as normal. The protective function of DAF was unable to be tested due to its reduced expression on isolated trophoblasts compared to normal placental tissue.

In rare cases, individuals deficient in DAF or CD59 have been reported, but no MCP deficiencies have been found. Individuals lacking DAF or CD59 survive pregnancy apparently unscathed making it unlikely that either regulator is essential for fetal survival but it is tempting to speculate that since there are no reported cases of individuals deficient in $\mathrm{MCP}$, this protein may have an essential role in complement inhibition in pregnancy. It is possible that the reason that this deficiency has not been identified is because it is without consequence (Morgan and Holmes, 2000). However, mutations in MCP have been identified in some patients predisposed to preeclampsia, leading to the suggestion that dysregulation of complement activation can be a risk factor for preeclampsia (Salmon et al., 2011). 
The most convincing evidence of complement inhibition in pregnancy comes from studies in mice and rats. These species express the three complement regulators detailed above but they also carry another regulator not found in other species called Crry (Trowsdale and Betz, 2006). Xu et al., 2000 generated mice that were deficient in Crry (Crry(-/)) and showed that survival of $\mathrm{Crry}(-/-)$ embryos was compromised due to complement deposition and placental inflammation. This study demonstrated that complement was responsible for the fetal loss as breeding to $\mathrm{C} 3(-/))$ rescued $\mathrm{Crry}(-/-)$ from lethality (Xu et al., 2000).

\subsection{Phosphocholination}

Phosphocholination is a post-translational modification which involves the addition of the small haptenic molecule phosphocholine to the polysaccharide moiety of certain secretory glycoproteins. This modification is characteristic of a wide variety of prokaryotic organisms (e.g. bacteria) as well as eukaryotic organisms (e.g. parasites). In parasites it has been suggested that phosphocholine containing proteins are secreted into host organisms and have an effect on immune cells leading to immunosuppression (Lovell et al., 2007). In particular, phosphocholinated proteins in filarial nematodes have been shown to inhibit normal proliferative responses of both $\mathrm{T}$ and $\mathrm{B}$ lymphocytes in vitro. These effects have been attributed to the phosphocholine moiety as phosphocholine coupled to bovine serum albumin has the same inhibitory effects on $\mathrm{T}$ and $\mathrm{B}$ lymphocytes as phosphocholinated filarial nematode proteins (Harnett and Harnett, 1993; Lal et al., 1990).

Recent studies have shown that phosphocholination can occur in mammalian species. Foulds et al., (Foulds et al., 2008) identified lyso-glycerophosphocholine as an endogenous immunosuppressive agent in bovine and rat gonadal fluids. In these studies, the immunosuppressive fractions of rat testicular interstitial fluid and bovine ovarian follicular fluid were assayed by sequential reverse phase high performance liquid chromatography (HPLC) and sequenced using capillary electrophoresis electrospray ionization mass spectrometry. These molecules were shown to inhibit $\mathrm{T}$ cell proliferation and induce apoptosis of T cells in a time and dose dependent manner (Foulds et al., 2008).

In the placenta, Lovell et al., (Lovell et al., 2007) showed that a large number of placental polypeptides and proteins carry phosphocholine as a tissue specific post translational modification and suggested the presence of phosphocholine groups on placental secretory proteins and peptides may play a major role in maternal immune tolerance during pregnancy. In these studies, placental neurokinin B and the precursors of corticotropin releasing hormone $(\mathrm{CRH})$, adrenocorticotropin, hemokinin, activin and follistatin were shown to be post-translationally modified by the addition of phosphocholine using a combination of HPLC and two site immunometric analyses. Lowry (Lowry, 2008) suggested that the addition of phosphocholine moieties in placental secreted peptides and proteins may be the rule rather than the exception and that this post translational modification may play an important role in maternal immune tolerance during pregnancy.

\subsection{Programmed Death Ligand 1 (PDL1)}

The activation of $\mathrm{T}$ lymphocytes requires two signals, one of which is delivered by the $\mathrm{T}$ cell receptor complex after antigen recognition and the other which requires the engagement of costimulatory receptors. The second signal can be either positive, which leads to full $\mathrm{T}$ cell 
activation, or negative, which can downregulate immune responses (Rothstein and Sayegh, 2003). In regards to negative $T$ cell signaling, the inhibitory costimulatory receptor molecule programmed death 1 (PD1) and its ligands, PDL1 and PDL2 have been shown to play a role in regulating immune responses in vivo (Guleria et al., 2005).

PD1 is a 55kDa type 1 transmembrane receptor that was initially identified in a murine Tcell hybridoma undergoing activation induced cell death (Ishida et al., 1992) and is a member of the CD28 IgG superfamily (Rothstein and Sayegh, 2003). It has been shown to be constitutively expressed by double negative thymocytes (hematopoietic progenitor cells present in the thymus which are negative for CD4 and CD8) and natural killer (NK) cells, and its expression can be induced on activated CD4 and CD8 T cells, B cells and macrophages. The ligands for PD1, PDL1/2, are expressed on antigen presenting cells following cellular activation or exposure to interferon gamma (IFN- $\gamma)$. PDL-1 has also been found on a subpopulation of activated T cells. In addition, the ligands can be constitutively expressed or induced by a variety of parenchymal or endothelial cells, including heart, kidney, pancreas and placenta (Blank et al., 2005).

Binding of either ligand to PD1 inhibits antigen stimulated T cell activation through several mechanisms including the control of proliferation, alteration of cytokine production, and the induction of apoptosis (Blank et al., 2005; Hori et al., 2006). In vivo studies have shown the critical importance of PD1 in maintaining immunological self tolerance. PD1 knockout mice have fatal autoimmune disease and in humans, polymorphisms in PD1 are associated with several autoimmune diseases (Nishimura and Honjo, 2001; Prokunina et al., 2002). Further, this inhibitory receptor and its ligand have also been shown to prevent allograft rejection suggesting an important role in negative T cell signaling (Wang et al., 2007).

As a result of their established role in negative $\mathrm{T}$ cell signaling, it was hypothesized that PD1/PDL(1/2) signaling may play an important role in maternal immune tolerance. During pregnancy, PDL2 is expressed on the syncytiotrophoblast in early pregnancy, while PDL1 is expressed on all trophoblast populations throughout pregnancy. Expression of PDL1 is low in first trimester placenta and increases throughout gestation whereas PDL2 is prominent in the syncytiotrophoblast of the early placenta and decreases throughout gestation (Petroff et al., 2003; Petroff et al., 2005). Interestingly, in the mouse the source of PDL1 is the maternal decidua and not the trophoblast suggesting that the decidua may participate in the suppression of alloantigen specific T cells.

Experimental studies on mice using blocking antibodies against PDL1 and PDL2 showed a dramatic loss of allogeneic fetuses in animals treated with the PDL1 but not PDL2 blocking antibody. No effect of the inhibition of PDL1 signaling was observed in syngeneic fetuses suggesting that PDL1 is participating in maternal immune tolerance (Guleria et al., 2005). However, in contrast to the above study, Taglauer et al. (Taglauer et al., 2009), showed that the absence of maternal PD1 and PDL1 had no detectable effects on gestation length, litter size, or pup weight at birth in both syngeneic or allogeneic pregnancies. The discrepancies between the two studies are hard to explain but the lack of rejection seen in Taglauer et al., (Taglauer et al., 2009) may be explained by the existence of redundant or compensatory immunosuppressive mechanisms at the maternal fetal interface.

As detailed above, The PD1/PDL1 pathway can inhibit $\mathrm{T}$ lymphocytes through several mechanisms. In regards to maternal immune tolerance, it has been speculated that the role 
of PD1/PDL1 in maternal-fetal tolerance is to control the abundance of T cells by inducing apoptosis of paternal antigen specific T cells. Taglauer et al., 2009 (Taglauer et al., 2009) showed that fetal antigen-specific lymphocytes upregulate PD1 following recognition of fetal antigen. In the absence of PD1, lymphocytes were seen to accumulate in the maternal uterine draining lymph nodes suggesting that PD-1 may be responsible for their deletion.

\subsection{Major Histocompatibility Complex (MHC) and the non-classical Human Leukocyte Antigen (HLA) class 1bGenes (HLA-E, -G and -F) expressed on Trophoblast cells}

All mammalian species studied to date possess a tightly linked cluster of genes, the Major Histocompatibility Complex (MHC) complex, which are involved in intercellular immune recognition and antigen presentation to $\mathrm{T}$ lymphocytes. Based on the observation that in most of the cases of transplant rejection the immune response is directed against a few proteins encoded by the MHC genetic region, the study of the immunological status of the mammalian fetus has been primarily directed towards determining which MHC are expressed on trophoblast cells (Bainbridge, 2000). The MHC, which is referred to as the Human Leukocyte Antigen (HLA) complex in humans, is organized into three regions based on the types of molecules that are produced. Class I molecules encode glycoproteins which are expressed on the surface of nearly all nucleated cells, class II molecules encode glycoproteins primarily expressed on antigen presenting cells and class III molecules encode secreted proteins associated with the immune process (e.g. soluble serum proteins) (Kuby, 1997).

In organ transplantation, allelic differences between MHC class II and class I molecules form the primary basis for transplant rejection. Therefore it is relevant to note that trophoblast cells of the placenta are unique because they are one of the few mammalian cell types that do not express classical MHC class II antigens, either constitutively or after exposure to IFN$\gamma$ (Murphy et al., 2004). This is arguably one of the most important immune evasion strategies during pregnancy.

Initially it was thought that trophoblast cells did not display HLA antigens and that this phenomenon could completely account for immunological protection of the fetus (Faulk and Temple, 1976; Goodfellow et al., 1976; Hunt et al., 1988). It was later discovered that placental cells express specific genes within the MHC loci. The expressed class I genes are subdivided into class Ia, which includes HLA-A, -B, and -C, and class Ib, which includes HLA-E, -F, and -G. Human trophoblast cells do not express the two main polymorphic classical class Ia antigens HLA-A and B (Redman et al., 1984) and only express one class Ia molecule (HLA-C) and all three class Ib molecules. These class Ib antigens are distinguished by low numbers of alleles that differ at the protein level.

HLA-G was the first trophoblast HLA molecule to be identified and is of great interest due to the strong evidence which suggests that this class Ib molecule may be important in preventing maternal immune attack against the fetus during pregnancy (Le Bouteiller, 1996). Interestingly, HLA-G like proteins have also been identified in the placentas of nonhuman primates supporting the concept that HLA-G like proteins may be important in maternal immune tolerance.

HLA-G can be expressed as seven isoforms, of which four are membrane bound (HLA-G1 to G4) and three are soluble (HLA-G5 to -G7) (Carosella et al., 2008). In contrast to classical 
HLA alleles, HLA-G has a very low level of polymorphism with only 8 protein variants. Most of the polymorphisms that are encountered in the HLA-G gene are not predicted to alter the amino acid sequence, or, if they do, will not change the secondary structure of the molecule. Due to the low level of polymorphisms, paternal HLA-G expressed on the surface of trophoblast cells will be almost identical to maternal HLA-G. This minimizes the risk of immune rejection.

Early studies identified HLA class I antigen expression as being specific to extra-villous trophoblast (EVT) populations, with the proteins being prominent in cells adjacent to the decidua throughout gestation (Hunt and Langat, 2009). However, the antibody used to identify these antigens required MHC light chain and MHC heavy chain associations which are not present on all HLA-G isoforms. More recent studies using different antibodies which are capable of detecting previously undetectable HLA-G alleles showed that HLA-G isoforms are present throughout the placenta and within the chorion membrane, decidua and maternal blood (Hunt and Langat, 2009).

Since HLA-G is produced at high levels at the maternal interface it has been suggested to have a role in maternal tolerance induction. The effects of HLA-G in different tissues include impacts on NK cell killing activity, migration and cell viability, proliferation and IFN- $\gamma$ production, regulation of cytokine production, suppression of cytotoxic $\mathrm{T}$ lymphocyte killing activity and viability, inhibition of proliferation and induction of a suppressive phenotype in $\mathrm{T}$ helper cells, and alteration of dendritic cell stimulatory capacity and maturation of this lineage (reviewed in (Hunt, 2006)).

There are currently no reported cases of pregnancy from women in which all the forms of the HLA-G are absent. However, mutations in HLA-G alleles have been identified. For example, Ober et al., (Ober et al., 1998) identified a single base pair deletion at position 1597 of exon 3 of HLA-G which is present on $7.4 \%$ of African American and $2.9 \%$ Hispanic chromosomes. This deletion causes a frameshift mutation and results in amino acid substitutions in all of the residues of the second half of exon 3. Individuals with this mutation, have no detectable HLA-G1 protein but are still able to go through normal pregnancy suggesting that certain HLA-G alleles are not essential for pregnancy. Other studies have shown that certain polymorphisms such as a 14 base pair insertion in exon 8 of the 3'-UTR may be associated with pregnancy complications such as preeclampsia and recurrent spontaneous abortion (Larsen and Hviid, 2009). However, these data are not well supported in the literature and different studies show different effects of HLA-G polymorphisms.

Studies of MHC molecules in the trophoblast of the mouse have shown that mice predominantly express only one MHC class I antigen, $\mathrm{H}-2 \mathrm{~K}$, at the cell surface of trophoblast giant cells and appear to lack the expression of non-classical MHC molecules (Madeja et al., 2011). However, recent studies have hypothesized that mice may have a functional homolog of HLA-G, with both Qa-2 and Blastocyst MHC being postulated to play this role. The mouse Qa-2 gene has some of the structural characteristics of HLA-G and is expressed on pre-implantation embryos (Comiskey et al., 2003) while Blastocyst MHC is selectively expressed in the blastocyst and placenta (Tajima et al., 2003). Interestingly, both of these putative homologs have been implicated in immune regulation (Comiskey et al., 2003; Tajima et al., 2003) suggesting that they may play a similar role to HLA-G. 
Altogether, these data suggest that non-classical MHC molecules may play an important role in the generation of maternal immune tolerance.

\subsection{Tryptophan catabolism mediated by indoleamine 2,3,-dioxygenase (IDO)}

Indoleamine 2,3-dioxygenase (IDO) is an enzyme that catabolizes the essential amino acid Ltryptophan that is required for the biosynthesis of proteins. IDO was initially described in 1967 by Yamamoto and Hayaishi in the rabbit intestine as an enzyme that could oxidize both L- and D-tryptophan (Yamamoto and Hayaishi, 1967) and was later shown to have an important role in microbial resistance by allowing cells to deplete tryptophan from intracellular pools or the local microenvironment (Mellor and Munn, 1999). When an infectious agent invades a tissue, leukocytes and lymphocytes accumulate at the site of infection and secrete IFNs into the inflammatory milieu. The presence of IFN triggers IDO production and subsequent tryptophan catabolism which inhibits the growth of the infectious agent (Grohmann et al., 2003).

As tryptophan is an indispensible requirement for cell growth, it was proposed that IDO may have other important roles. Indeed, there are intriguing associations between altered tryptophan metabolism and cell-mediated immune responses. For example, enhanced tryptophan catabolism by macrophages has been shown to inhibit $\mathrm{T}$ cell proliferation and it appears that the expression of IDO by cells allows them to suppress unwanted $\mathrm{T}$ cell responses (Munn et al., 1999). Further, emerging evidence is linking the IDO pathway with T-regulatory (Treg) cell biology. Firstly, studies have shown that IDO competent dendritic cells can drive the generation of Tregs through high levels of IDO. Secondly, IDO can prevent the reprogramming of Tregs into proinflammatory T-helper-like cells in vivo (Munn, 2011). In support of the above statements, studies have shown that patients receiving tryptophan for a variety of disorders experience a high frequency of autoimmune disease (Mellor and Munn, 1999). In addition, studies of the potential role of IDO in transplantation tolerance have shown that the presence of this enzyme in pancreatic islet, lung, heart and corneal allografts can significantly extend graft survival (reviewed in (Mulley and NikolicPaterson, 2008). Collectively, these data suggest that IDO can modulate immunity.

IDO expression is not detected in most tissues of healthy mammals but can be increased by infection and inflammation due to the production of IFNs and other factors (Baban et al., 2004). The only tissues where IDO is expressed at constitutively high levels is the proximal male epididymis and at the maternal-fetal interface during mammalian pregnancy (Baban et al., 2004). Munn et al., (Munn et al., 1998) proposed that in the mouse the expression of IDO by the placenta is crucial in the prevention of T cell responses against the fetus. In this study Munn et al., demonstrated that tryptophan is catabolized by the placenta during pregnancy and that this process suppresses $T$ cell activity and defends the fetus against rejection. Rapid $\mathrm{T}$ cell-induced rejection of all allogeneic but no syngeneic fetuses occurred when pregnant mice were treated with the IDO inhibitor, 1-methyl-tryptophan (Munn et al., 1998).

In humans, Kudo et al., showed that IDO activity and messenger RNA (mRNA) expression can be positively regulated by cytokines such as IFN- $\gamma$ and that tryptophan transport into the trophoblast is the rate limiting step for IDO mediated tryptophan degradation (Kudo and Boyd, 2000; Kudo and Boyd, 2001). Knowing that IDO had similar actions in humans as in mice, Kudo et al., examined the potential role of IDO in the human placenta. In these 
studies, Kudo et al., showed that tryptophan degradation by IDO inhibited lymphocyte proliferation in placental tissues. Media conditioned by placental villi in the presence of IFN-ץ (inducer of IDO) was more depleted of tryptophan than control media and the proliferation of mononuclear cells, specifically $\mathrm{CD} 4^{+} \mathrm{T}$ lymphocytes was markedly inhibited by tryptophan degradation. This inhibition could be reversed by the addition of 1-methyl tryptophan (Kudo et al., 2001).

Despite all of these reports which support a role for IDO in maternal immune tolerance, a number of studies have shown that IDO is not essential for pregnancy. Baban et al., developed an IDO knockout mouse and showed that in allogeneic matings, the mice were capable of producing litters of normal sizes and rates compared to control mice suggesting that redundant mechanisms may protect allogeneic fetuses in IDO knockout mice (Baban et al., 2004). Also, in humans it has been reported that IDO expression does not differ between proven fertile women and women with a history of miscarriages.

\subsection{Progesterone}

Since the 1970s, evidence detailing the production of various hormones and cytokines by the placenta has expanded our knowledge on mechanisms by which uterine tissue functions as well as the putative roles of these hormones and cytokines in pregnancy (Petraglia et al., 1996). The production and modulation of hormones during pregnancy is essential and many important processes, such as the transport of sperm and oocytes, implantation and labor are controlled by alterations in the hormonal environment (Szekeres-Bartho, 2002). Placental steroid hormones have also been considered as possible mediators of immunosuppression during pregnancy because of the immunosuppressive properties of natural and synthetic glucocorticoids (Siiteri et al., 1977).

Among the hormones present in maternal serum, progesterone, the hallmark of pregnancy, appears to play a major role in reducing the maternal response to the fetal allograft (Beagley and Gockel, 2003). Progesterone has been shown to be essential in the maintenance of pregnancy in a number of mammalian species. In humans, progesterone is produced autonomously by the placenta at high levels (up to $250 \mathrm{mg}$ a day) (Szekeres-Bartho, 2002). Shortly after delivery the concentration of progesterone in maternal blood falls precipitously.

Early studies showed that high concentrations of progesterone can prolong the survival of xenogeneic and allogeneic grafts (reviewed in (Szekeres-Bartho, 2002)). For example, Hansen et al., (Hansen et al., 1986) studied the effect of progesterone on skin transplants placed in the uterine lumen of ovariectomized ewes. Allografts placed in the uterine lumen of progesterone treated ewes were present 30 days after engraftment while allografts placed in control animals were completely resorbed. Other studies have shown that progesterone can affect various phases of the immune response in vivo. Siiteri et al (Siiteri et al., 1977) showed in rats, using progesterone concentrations that mimic the high intrauterine concentration in pregnancy, that progesterone can effectively block cellular immune responses both in vitro and in vivo. Stites et al., (Stites et al., 1983) using human blood cultures showed that progesterone was capable of inhibiting monocyte dependent $\mathrm{T}$ cell activation. 
Progesterone can induce its immunological changes by a number of different cellular and molecular mechanisms. It has been shown to stimulate the activity of specific enzyme matrix metalloproteinases and adhesion molecules, inhibit antibody production and suppress T-cell activation and cytotoxicity, modify the activity of natural killer cells and induce the secretion of protective asymmetric antibodies (reviewed in (Kyurkchiev et al., 2010).

In pregnancy, the immunosuppressive effects of progesterone are determined on the one hand by its concentration and also by the progesterone-binding capacity of lymphocytes. Lymphocytes carried by the maternal blood during pregnancy are extremely sensitive to progesterone which suggests receptor mediated action of progesterone on the lymphocytes. Szekeres-Batho et al., (Szekeres-Bartho et al., 1990) showed that CD8 ${ }^{+}$lymphocytes produced peripherally during pregnancy were reactive to progesterone receptor monoclonal antibodies and that the level of progesterone receptor positive lymphocytes increased throughout gestation.

The biological effects of progesterone during pregnancy are manifested by a 34kDa protein, called the progesterone induced blocking factor (PIBF), which is released by lymphocytes of pregnant women following binding of progesterone to its receptors (Szekeres-Bartho, 2002). In pregnant women, the PIBF concentration gradually increases until the $37^{\text {th }}$ week of gestation, followed by a slow decrease until term. PIBF signals through the JAK/STAT pathway and has been shown to: alter the cytokine balance resulting in a preferential production of Th2 type cytokines in mice, inhibit NK cell activity through mediation by cytokines, and regulate anti-abortive effects (Kozma et al., 2006; Szekeres-Bartho, 2002; Szekeres-Bartho and Wegmann, 1996; Szekeres-Bartho et al., 2008). In peripheral blood of healthy pregnant women, the percentage of PIBF positive lymphocytes is significantly higher in all trimesters of pregnancy than in women at risk for premature pregnancy termination (Szekeres-Bartho et al., 1995).

Interestingly, recent studies have suggested that progesterone may have a role in the generation of Treg cells in both mice and humans. In these studies, physiological doses of progesterone were shown to significantly increase the population of Treg cells (Lee et al., 2011; Mao et al., 2010). However, in contrast to these data, Mjosberg et al. showed using an in vitro model, that progesterone reduced the Treg cell population in PBMC from nonpregnant women (Mjosberg et al., 2009). While the potential role of progesterone in the stimulation of Treg cells is exciting, further studies are required.

\subsection{Th1-Th2 cytokine balance in pregnancy}

The best studied peripheral immune cells in pregnancy are T-lymphocytes. Within this population there are two main subsets which are defined as helper $\mathrm{T}$ lymphocytes and cytotoxic T lymphocytes. Helper T lymphocytes are particularly important in the context of pregnancy as they affect the function of other immune cells by producing cytokines (Veenstra van Nieuwenhoven et al., 2003). Helper T lymphocytes can be further separated into Th1 and Th2 based on their profile of cytokine production. Th1 produce tumor necrosis factor (TNF)- $\alpha$, IFN- $\gamma$ and interleukin (IL)-2 which promote cellular immune responses while Th2 produce IL-4, IL-5, IL-9, IL-10 and IL-13 which promote humoral responses (Mosmann et al., 1986; Veenstra van Nieuwenhoven et al., 2003). 
It has been shown that $\mathrm{T}$ cells mediate many of their effects through the secretion of cytokines and in pregnancy it has been hypothesized that a correctly regulated cytokine environment determines the growth and survival of the feto-placental unit. Studies by Chaouat et al., (Chaouat et al., 1995; Chaouat et al., 1990) examined fetal survival following the injection of various cytokines in mice and showed that granulocyte macrophage colony stimulating factor (GM-CSF), IL-3 and IL-10 enhanced fetal survival and promoted intrauterine growth while TNF- $\alpha$, IFN- $\gamma$ and IL-2 had deleterious effects which led to fetal death. These studies, and the studies of others led to the Th1/Th2 paradigm proposed by Wegmann et al., in 1993 (Wegmann et al., 1993) which hypothesized that Th2 cytokines inhibit Th1 responses, improving fetal survival and impairing responses against some pathogens. It is important to note that this hypothesis was in reference to the postimplantation period till labor (Chaouat, 2007) and was never meant to be extended to implantation and conception where inflammatory cells and molecules play an important role in preparing the female reproductive tract for pregnancy (Robertson, 2010).

As detailed above, the Th1/Th2 paradigm stated that "successful pregnancy is a Th2 phenomenon " (Wegmann et al., 1993). Indeed, pregnancy is characterized by an increase in Th2 immune responses. Studies in humans and in mice have shown that the maternal immune response is biased toward a Th2 humoral response and away from cell-mediated immunity which could be harmful to the fetus (Raghupathy, 1997; Wegmann et al., 1993). In women who suffer from recurrent spontaneous abortions their peripheral blood mononuclear cells (PBMCs) respond in vitro to trophoblast antigens by producing high levels of the Th1 cytokine IFN- $\gamma$ and TNF-a (Chaouat et al., 1990; Hill et al., 1995). Conversely, in PBMC from women who are not prone to recurrent spontaneous abortions a preferential production of the Th2 cytokine IL-10 is observed (Hill et al., 1995). It is also interesting to note that humoral associated autoimmune diseases such as lupus tend to flare up during pregnancy while cell-mediated ones such as rheumatoid polyarthritis, often enter remission (reviewed in (Chaouat, 2007)).

Several different cells and soluble factors have been proposed as potential regulators of the altered Th1/Th2 ratio characteristic of pregnancy. The syncytiotrophoblast and cytotrophoblast are known to produce cytokines and these cells can influence cytokine production by acting on the Th1/Th2 balance (de Moraes-Pinto et al., 1997). Decidual cells and cells of the uterine draining lymph node have also been shown to suppress immune responses in vitro. Factors such as progesterone, PIBF and IDO have been proposed to alter the Th1/Th2 balance and cytokines themselves may play extremely important roles in modifying the immune system to favor a Th2 environment. Both transforming growth factor (TGF)- $\beta$ and IL-10 appear to assist in maintaining the Th1/Th2 balance. IL-10 plays an important role in preventing spontaneous pregnancy failure in mice. The injection of IL-10 alone into pregnant mice has been shown to lead to the prevention of fetal resorption. This effect can be reversed by the addition of anti-IL-10 antibodies (Chaouat et al., 1995). TGF- $\beta$ has been correlated with the immunosuppressive activity of decidual supernatants, appears to be reduced or absent in mice undergoing fetal resorptions and also appears to have an essential role in priming the immune system to tolerate seminal antigens (Raghupathy, 1997; Robertson et al., 2002).

However, Th2 dominant immunity has also been observed in recurrent abortion cases and Th2 knockout mice can proceed normally through a pregnancy suggesting that in addition 
to the Th1/Th2 phenomena, there are other mechanisms which may contribute to maternal immune tolerance (Chaouat et al., 2003). With this in mind, the Th1/Th2 paradigm has been expanded into the Th1/Th2/Th17/Treg paradigm. In this paradigm, Th17 cells, which produce IL-17 and are reported to be expressed at high levels in spontaneous abortion, are mediators of inflammation along with Th1 cells, while Treg cells which are potent suppressors of inflammatory immune responses and are essential to prevent autoimmunity (Saito et al., 2010), may be important in the induction of antigen specific tolerance.

TGF- $\beta$ super family members are pleiotropic cytokines with well-known roles in a wide range of developmental processes including tissue differentiation, morphogenesis, proliferation, and migration. TGF- $\beta 1$, TGF- $\beta 2$ and TGF- $\beta 3$ are abundant in mammalian reproductive tissues. TGF- $\beta$ fulfils a pivotal role in the peripheral immune system through mediating the acquisition of immune tolerance (Schmidt-Weber and Blaser, 2004). TGF- $\beta$ can inhibit $\mathrm{T}$ helper type 1 (Th1) responses, which may be detrimental to pregnancy (Raghupathy, 2001), and is an important regulator of NK cell behavior, down-regulating IFN- $\gamma$ induced activation and inflammatory cytokine production. Lymphocyte populations secreting TGF- $\beta$ are causally linked with pregnancy success in mice (Arck et al., 1999) and are diminished in the event of miscarriage. Indeed, in mice prone to a high pregnancy failure rate, TGF- $\beta$ mRNA is significantly decreased in both uterine epithelial and metrial gland (NK) cells (Gorivodsky et al., 1999).

It has been reported that the intravaginal administration of bioactive TGF- $\beta 3$ can enhance success of pregnancy in vivo in an established mouse model of abortion (resorptions) (the $\mathrm{CBA} / \mathrm{J} \times \mathrm{DBA} / 2$ mouse model) (Clark et al., 2008). This result could be explained by the independent ability of TGF- $\beta$ to promote a Treg cell response.

Recent reports have suggested a role for TGF- $\beta$ in the generation of Treg cells from CD4+CD25- precursors (Ayatollahi et al., 2007; Chen et al., 2003; Zheng et al., 2007). These data suggest that Treg cells maintain transplantation tolerance through a TGF- $\beta$-dependent FOXP3 induction (Horwitz et al., 2008; Zheng et al., 2008). Thus, TGF- $\beta$ is a key regulator of the signaling pathways which initiate and maintain FOXP3 expression and suppressive function among CD4+CD25- precursors.

A reduction in TGF- $\beta 1$ has been observed in samples from non-pregnant women, compared with those of pregnant women, which might confirm the effect of TGF- $\beta 1$ in controlling the development and function of the immune system during pregnancy (Ayatollahi et al., 2007; Power et al., 2002).

In addition to the known individual effects of TGF- $\beta$ and IL-10 on lymphocytes and antigenpresenting cells, there is evidence for both cytokines working together to determine an immune response in a synergic way (Nagaeva et al., 2002). It has been shown that suppressive effects of TGF- $\beta$ and IL-10 added together is greater than each acting alone (Chen et al., 2003; Horwitz et al., 2003; Horwitz et al., 2008; Zheng et al., 2008).

In spite of TGF- $\beta$ having a central role in the induction of Foxp3 and regulatory capacity in $\mathrm{CD} 4+\mathrm{T}$ cells for transplantation tolerance, recently, however, the general anti-inflammatory role of TGF- $\beta$ in CD4+ T cell polarization has been questioned by the discovery that, in the presence of inflammatory cytokines such as IL- 6 or IL-1, TGF- $\beta$ drives the differentiation of Th17 cells associated with transplant rejection (Regateiro et al., 2011). 


\subsection{Regulatory T cells}

The term Tregs (regulatory T-cells) refers to a subpopulation of T-lymphocytes with pivotal suppressive/regulatory properties that are devoted to maintaining antigen-specific T-cell tolerance, diminishing destructive immune responses and preventing autoimmune disease. Three main subsets of $\mathrm{CD} 4+$ regulatory T-cells with distinctive suppressive mechanisms have been identified and can be distinguished by their phenotype, cytokine secretion and tissue origin. These are type 1 regulatory T-cells (Tr1), T-helper 3 cells and CD4+ CD25+ Treg cells. Each of these subsets has the capacity to inhibit the proliferation and effector function of other T cells. Treg cells have two main physiological roles: control T-cell reaction with self antigens that have escaped negative selection by the thymus, and limit the extent and duration of responses exerted by T-cells reactive with alloantigens and other exogenous antigens (Guerin et al., 2009).

Treg cells have fast become established as perhaps the most potent and widespread suppressive cell lineage in the immune system and they are involved in immune tolerance, autoimmunity, inflammation, transplantation and cancer (Guerin et al., 2009). Studies into the biological action of Treg cells have shown that they are potent suppressors of inflammatory immune responses and are an essential requirement to prevent autoimmunity and to promote the tolerance of allogeneic organ grafts (Groux et al., 1997; Kingsley et al., 2002). These unique properties of $T$ cells have led to speculation that they may have an important role in reproduction (Guerin et al., 2009).

Studies in mice have indicated that Treg cells are essential during the first days of pregnancy, even prior to embryo implantation. In mice, the Treg cell population expands as early as 2 days after mating where it is required to control the maternal immune response during peri-conception. It has been postulated that factors which promote the expansion of Treg cells are contained in seminal fluid. Soluble factors in seminal fluid such as members of the TGF- $\beta$ family and prostaglandins have previously been linked with the generation of Treg cells (Robertson et al., 2009). These early Treg cells play an important role in implantation as studies have shown that depletion of Treg cells prior to implantation leads to a reduction in the percentage of pregnant mice (Zenclussen et al., 2005).

Following implantation in the mouse, Treg cell number is seen to increase throughout gestation and these cells are able to suppress both autoimmune responses and allogeneic responses directed against the fetus. The physiological significance of $\mathrm{CD} 4{ }^{+} \mathrm{CD} 25^{+}$Treg cells in pregnancy was demonstrated in studies using an adoptive transfer model, where complete Tcell populations or populations depleted of $\mathrm{CD} 4{ }^{+} \mathrm{CD} 25^{+}$Treg cells were transferred into pregnant T-cell deficient mice. In these studies, Aluvihare et al., (Aluvihare et al., 2004) observed that in the absence of $\mathrm{CD} 4{ }^{+} \mathrm{CD} 25^{+}$Treg cells, allogeneic fetuses were promptly rejected, whereas syngeneic fetuses were unaffected. In addition, Zenclussen et al., (Zenclussen et al., 2005) showed that in vivo prevention of fetal rejection in abortion prone mice could only be achieved after adoptive transfer of Treg cells from normal pregnant mice.

A similar increase in Treg cell populations is evident in pregnant women. Studies have shown that circulating human $\mathrm{CD} 4{ }^{+} \mathrm{CD} 25^{+}$Treg cells increase throughout gestation with a peak during the second trimester and then a subsequent decline postpartum. Isolated human $\mathrm{CD}^{+} \mathrm{CD} 25^{+}$Treg were further shown to suppress proliferative responses of autologous $\mathrm{CD} 4{ }^{+} \mathrm{CD} 25$ - T-cells to allogeneic dendritic cells (Somerset et al., 2004). The role of 
Treg cells in maternal immune tolerance is further supported in studies which show that paternal antigen stimulation of Treg cells is required for optimal protection of fetuses from rejection. Mjosberg et al., showed that Treg cells from peripheral blood of pregnant and nonpregnant women can suppress alloantigen responses in vitro, with increased capacity to suppress anti-paternal as opposed to irrelevant alloantigens (Mjosberg et al., 2007).

The importance of Treg cells in pregnancy is further supported by studies of individuals who had complications of pregnancy. In preeclampsia, CD4+CD25high Treg cells are significantly reduced in both peripheral blood and decidual tissue compared to normal pregnant women (Sasaki et al., 2007). In spontaneous abortions, the levels of CD4 ${ }^{+} \mathrm{CD} 25^{+}$ Treg cells are significantly lower in patients who had a spontaneous abortion compared to samples from induced abortions (Sasaki et al., 2004). Unexplained infertility is also associated with a reduction in the expression of the Treg cell marker FOXP3 mRNA in endometrial tissue (Jasper et al., 2006). Furthermore, cells expressing the Treg cell activation marker CTLA-4 are more prevalent in peripheral blood and term deciduas of normal healthy pregnant women compared with non-pregnant women (Heikkinen et al., 2004). Therefore, impaired differentiation and recruitment of uterine Treg cells may increase the chance of pregnancy complications.

Collectively, these results suggest that Treg cells may have an important role in maternal immune tolerance.

\subsection{Corticotropin Releasing Hormone (CRH) and its regulation of FasL expression}

$\mathrm{CRH}$ is a 41 amino acid peptide hormone that acts as the main neurotransmitter orchestrating the stress response through the secretion of adrenocorticotropic hormone (ACTH) or corticotropin from corticotropes of the anterior pituitary (McLean and Smith, 2001; Vale et al., 1981). In addition to its function in the hypothalamic-pituitary-adrenal axis, expression of $\mathrm{CRH}$ has been recognized at several different sites, including the placenta (McLean and Smith, 2001).

Despite the knowledge of the role of $\mathrm{CRH}$ in the hypothalamic-pituitary-adrenal axis, the precise biological role/s for $\mathrm{CRH}$ in feto-maternal tissues are yet to be elucidated. In the placenta and fetal membranes $\mathrm{CRH}$ appears to have a wide variety of functions, including the regulation of trophoblast cell growth and invasion, tissue remodeling through the secretion of the matrix degrading protease matrix metalloproteinase 9, control of placental vascular tone through the activation of the nitric oxide pathway, direct modulation of endocrine function, especially prostaglandin generation and bioavailability, gestation length and the onset of labor (reviewed in (Grammatopoulos, 2008)). In addition to these roles, $\mathrm{CRH}$ is also known to have immunological effects.

Traditionally hypothalamic $\mathrm{CRH}$ has been considered to act indirectly in an anti-inflammatory fashion as the end product of the hypothalamic-pituitary-adrenal axis is cortisol which is a well known anti-inflammatory compound. However $\mathrm{CRH}$ produced at peripheral inflammatory sites has been shown to possess potent proinflammatory properties that can influence both innate and acquired immune responses (Kalantaridou et al., 2007). In the reproductive system, intrauterine and ovarian $\mathrm{CRH}$ can have proinflammatory properties. For intrauterine $\mathrm{CRH}$, various studies have shown that it may participate in the acute aseptic inflammatory response that is characteristic of embryo implantation (Makrigiannakis et al., 
2001). Ovarian CRH can also participate in the inflammatory processes of ovulation and luteolysis (Kalantaridou et al., 2007). However, following implantation, the embryo suppresses the inflammatory response and prevents immune rejection. It has been hypothesized that the anti-inflammatory role of CRH may play a role in this process through interactions with the proapoptotic cytokine, Fas Ligand (FasL) (Makrigiannakis et al., 2001).

FasL is a type II membrane protein of approximately 280 amino acids that belongs to the TNF superfamily. FasL has a high level of conservation amongst species and is highly expressed on several immune cells including activated $\mathrm{T}$ and B lymphocytes, NK cells, monocytes and macrophages. The major function of FasL is to induce apoptosis in cells which express its receptor, Fas (Lee and Ferguson, 2003). Fas, a membrane protein that belongs to the TNF and nerve growth factor receptor family, is also expressed at high levels in several immune cells, including activated B and T lymphocytes, NK cells, monocytes, and macrophages (reviewed in (Houston and O'Connell, 2004)). Due to the expression of Fas at high levels in several immune cells, it has been hypothesized that Fas/FasL interactions may be important in immune tolerance.

FasL expression has also been reported in nonhemopoietic cells, mainly from immuneprivileged tissues, including testis, cornea, trophoblast (Makrigiannakis et al., 2001), and cancer cells (Houston and O'Connell, 2004), suggesting that the Fas-FasL system may play an important role in the mechanism underlying this immune-privileged status (Griffith et al., 1995).

The Fas-FasL system is involved in apoptosis and is extensively used by the immune system during lymphopoiesis and immunopoiesis. It is also a major mechanism during clonal deletion of autoimmune cells inside the central and peripheral lymphoid organs and is involved in the cytolytic pathways of NK cells, Th1 cells and cytotoxic T cells. The Fas/FasL system is also implicated in the regulation of cellular turnover, tumor cell elimination, antiviral responses and protection of particular tissues against potential danger represented mainly by activated lymphocytes (reviewed in (Houston and O'Connell, 2004; Thellin et al., 2000)).

During human pregnancy, FasL is expressed on the trophoblast and decidualized endometrial cells. (Makrigiannakis et al., 2004; Taylor et al., 2006). Studies on placental exosomes have also shown the presence of cytoplasmic microvesicular forms of FasL in syncytiotrophoblast (Frangsmyr et al., 2005) and its secretion into maternal blood (Taylor et al., 2006). As a result of this expression profile, FasL has been speculated to have a role in embryo implantation and maternal immune tolerance. Makrigiannakis et al., (Makrigiannakis et al., 2001) examined the role of FasL in implantation and early pregnancy and showed that CRH increased FasL expression in human EVT cells which in turn increased the levels of activated $\mathrm{T}$ cell apoptosis in PBMC isolated from newborn children. Neutralizing antibodies to FasL were shown to inhibit CRH-induced apoptosis suggesting that this effect was mediated by Fas/FasL interactions.

To determine the relevance of these in vitro findings, Makrigiannakis used an in vivo rat model to study embryo implantation. These studies showed that administration of the CRHR1 antagonist, antalarmin, to female rats resulted in a marked decrease in FasL expression, implantation sites and live embryos. As with the in vitro studies, these studies showed that this was a $\mathrm{T}$ cell dependent process as $\mathrm{T}$ cell deficient rats treated with antalarmin had no difference in the number of implantation sites compared to control animals (Makrigiannakis et al., 2001). 
However, as with IDO and PDL-1, studies have shown that Fas/FasL interactions are not obligatory for successful pregnancy. Hunt et al., (Hunt et al., 1997) examined whether the absence of FasL affected pregnancy using gld mice (mice unable to express a functional FasL). In these mice, extensive leukocytic infiltrates and necrosis at the decidual-placental interface were observed which resulted in increased embryo resorption and a decrease in litter size. Interestingly, the lack of FasL in this mutant strain did not abrogate fertility suggesting that there may be other mechanisms which can control the maternal immune response in the absence of FasL.

\subsection{Placental endogenous retroviral envelope proteins}

Retroviruses can be defined as a class of enveloped viruses that have their genetic material in the form of RNA and use the enzyme reverse transcriptase to translate their RNA into DNA in a host cell (Ryan, 2004). All retroviruses contain information coding for three defined sets of regions of genes: gag (group specific antigen), pol (polymerase) and env (envelope). Gag directs the synthesis of internal virion proteins that form the capsid and nucleoprotein structure; pol contains the information for the reverse transcriptase and integrase enzymes and env contains the surface and transmembrane subunits of the virion envelope protein, which are involved in cell fusion, immunosuppression and receptor recognition (Sandrin et al., 2004).

Human endogenous retroviruses (HERVs) are evolutionary fossils inherited in a Mendelian fashion and are derived from retroviruses which, at some ancient time-point, have infected germline cells (Urnovitz and Murphy, 1996) and because of that, they are present in all human cells. HERVs represent about $8 \%$ of the human genome (Ryan, 2004). The analysis by Tristem (Tristem, 2000) confirms previous reports that the vast majority of HERV elements are defective by virtue of deletions or stop codons in gag, pol or env genes. Although many HERVs are defective, some still have open reading frames that are free from deletions and mutations. From these sequences, several types of expression are seen, from subgenomic and full length RNA transcripts, to complete retroviral particles with polymerase and protease activity.

The most abundant expression of different HERVs is seen in the placenta and embryonic tissues, and other reproductive tissues or cells, such as the testis and oocyte. From as early as the 1970s repeated electron microscope observations have been made of the presence of C-type ERVs within both human and animal placental tissue (Harris, 1991). The presence of ERV particles and proteins in these tissues suggests a normal function for these proteins in this environment (Mwenda, 1994).

In 1999, Blond et al. (Blond et al., 1999) described a HERV env gene belonging to the HERV$\mathrm{W}$ family encoding a protein expressed in the syncytiotrophoblast which was called syncytin by Mi et al. (Mi et al., 2000). Syncytin (syncytin-1) was shown to fuse human trophoblasts cells and it has been proposed that syncytin-1 may be a key factor in regulating syncytialization during placenta formation (Blond et al., 2000; Mi et al., 2000). Later on, a second fusogenic envelope protein belonging to the HERV-FRD family was identified in the placenta and named syncytin-2 (env-FRD) (Blaise et al., 2003). We now know that human (Blaise et al., 2003; Mi et al., 2000), mouse, rat, gerbil, vole, hamster (Dupressoir et al., 2005), rabbit (Heidmann et al., 2009) and most recently bovine (Koshi et al., 2011) all express in 
their placenta, endogenous retroviral envelope proteins which appear to play an important biological role.

In addition to their role in cell-cell fusion, it has been hypothesized that placental ERV envelope proteins may have a role in maternal immune tolerance (Mangeney et al., 2007). Retroviral infections are commonly associated with immunosuppression in many species which can result in susceptibility to other infections (Haraguchi et al., 1997). The majority of studies on the immunosuppressive effects of retroviruses have focused on exogenous retroviruses (Blaise et al., 2001; Mangeney and Heidmann, 1998; Peterson et al., 1963) however there is growing evidence that ERVs may play an immunosuppressive role at the maternalfetal interface (Mangeney et al., 2001; Villarreal, 1997). The source of this immunosuppression is a highly conserved amino acid sequence called the immunosuppressive domain (ISD) present in the transmembrane subunit of the envelope protein of most retroviruses (Cianciolo et al., 1985). Both syncytin-1 and syncytin-2 carry a sequence with a degree of homology to the ISD.

A synthetic peptide with the 17 amino acid consensus sequence of the ISD called CKS-17, was originally produced by Cianciolo et al., (Cianciolo et al., 1985) and has been extensively studied (reviewed in (Haraguchi et al., 2008)). Initially, CKS-17 was shown to inhibit the proliferation of an IL-2 dependent murine cytotoxic T cell line as well as alloantigen stimulated proliferation of murine and human lymphocytes (Cianciolo et al., 1985). Since these initial studies by Cianciolo, CKS-17 has been shown to have important immunological effects ultimately resulting in an inhibition of cell-mediated immunity (Th1 type responses) and a shift towards humoral immunity (Th2 type responses) (Haraguchi et al., 2008). The maintenance of pregnancy has also been correlated with a shift from Th1 to Th2 type immune responses (Wegmann et al., 1993).

The immunosuppressive properties of the retroviral ISD have been further explored in vivo. Exogenous retroviral envelope proteins from MMuLV (Mangeney and Heidmann, 1998) and Mason Pfizer Monkey Virus (MPMV) (Blaise et al., 2001) as well as the endogenous HERV$\mathrm{H}$ (Mangeney et al., 2001) have been shown to have immunosuppressive properties using an in vivo mouse tumor model. Allogeneic tumor cells that would normally be rejected by the mice were transfected with the envelope protein of the retroviruses and tumor cell growth and proliferation was examined. Retroviral envelope expression was able to block immunemediated elimination of the tumor cells (Blaise et al., 2001; Mangeney et al., 2001; Mangeney and Heidmann, 1998). Interestingly, in studies on MPMV, this immunosuppression was shown to be specific to tumor cells expressing the envelope protein, as tumor cells not expressing the envelope protein injected simultaneously into the same mouse were rejected (Mangeney and Heidmann, 1998).

Mangeney et al., 2007 (Mangeney et al., 2007) provided the first evidence for an immunosuppressive function for placental syncytins. Human syncytin-1 and -2 , and mouse syncytin-A and -B were transfected into an allogeneic tumor cell line and transplanted subcutaneously into mice. Tumor cell growth was used as a measure of immunosuppression. This study showed that in both humans and mice, one of the two syncytin proteins (syncytin-2 in humans, syncytin-B in mice) was immunosuppressive, while the other is not (syncytin-1 in humans, syncytin-A in mice). 
To further characterize placental syncytins immunosuppressive properties, Mangeney analyzed the humoral immune response of syncytin- 1 and -2 using recombinant syncytin ectodomains, which are 63- or 64-residue-long fragments respectively and which include the ISD. These ectodomains are large enough to adopt the proper physiological conformation (Kobe et al., 1999; Mangeney et al., 2007; Renard et al., 2005). An assay was designed based on the production of antibodies by mice injected with the purified ectodomain. The human syncytin ectodomain proteins were injected twice at a 1 week interval and sera were collected 4 days after the last injection for analysis of IgG titers. The results showed that a humoral response was only mounted against the "non-immunosuppressive" syncytin-1 suggesting that syncytin-2 had no stimulatory effect on the production of antibodies (Mangeney et al., 2007).

The findings of Mangeney et al., (Mangeney et al., 2007) are rather puzzling as the localization of the immunosuppressive syncytin-2 is within the villous cytotrophoblast cells where it is not directly exposed to the maternal circulation while syncytin- 1 is localized in the maternal blood bathed syncytiotrophoblast (Kudaka et al., 2007; Malassine et al., 2008). Also, while syncytin-1 levels have been shown to increase throughout pregnancy, syncytin-2 has a decreasing pattern of expression (Okahara et al., 2004). Transcriptional levels of syncytin-2 are also about 10-fold lower than syncytin- 1 in the first trimester and 40 -fold lower at term.

To our knowledge, no further studies have been completed on the immunosuppressive properties of syncytin-2, -A and -B so further analysis of these proteins are required. In regards to syncytin-1, it is clear that the current knowledge on the involvement of this protein in maternal immune tolerance requires further characterization. However, it is clear from these studies that placental retroviral envelope proteins may contribute to the altered maternal immune environment during pregnancy.

\subsection{Placental exosomes}

Recently it has become apparent that placental exosomes also may play an important role in maternal immune tolerance (reviewed in (Mincheva-Nilsson and Baranov, 2010)). The authors would like to point the reader's attention to Chapter: 12. by Lucia Mincheva-Nilsson and Vladimir Baranov for a detailed review on the role of placental exosomes in immune modulation.

\section{Conclusion}

Despite over half of a century of systematic research and the advance of new and more precise research methods on the mechanisms behind maternal immune tolerance, there is still no answer to the question originally formulated by Medawar: "How does the pregnant mother contrive to nourish within itself, for many weeks or months, a foetus that is an antigenically foreign body?" (Medawar, 1953). Undoubtedly more research needs to be done in this field to allow a better understanding of the critical mechanisms involved in maternal immune tolerance. The mechanisms that are detailed above (for overview of the mechanisms discussed, please refer to Figure 1) are all capable of inducing immune tolerance, but not all of them are necessarily required for pregnancy to be successful (Baban et al., 2004; Chaouat et al., 2003). There appear to be many redundant mechanisms that exist to provide robustness to the system that is essential for mammalian pregnancy. 


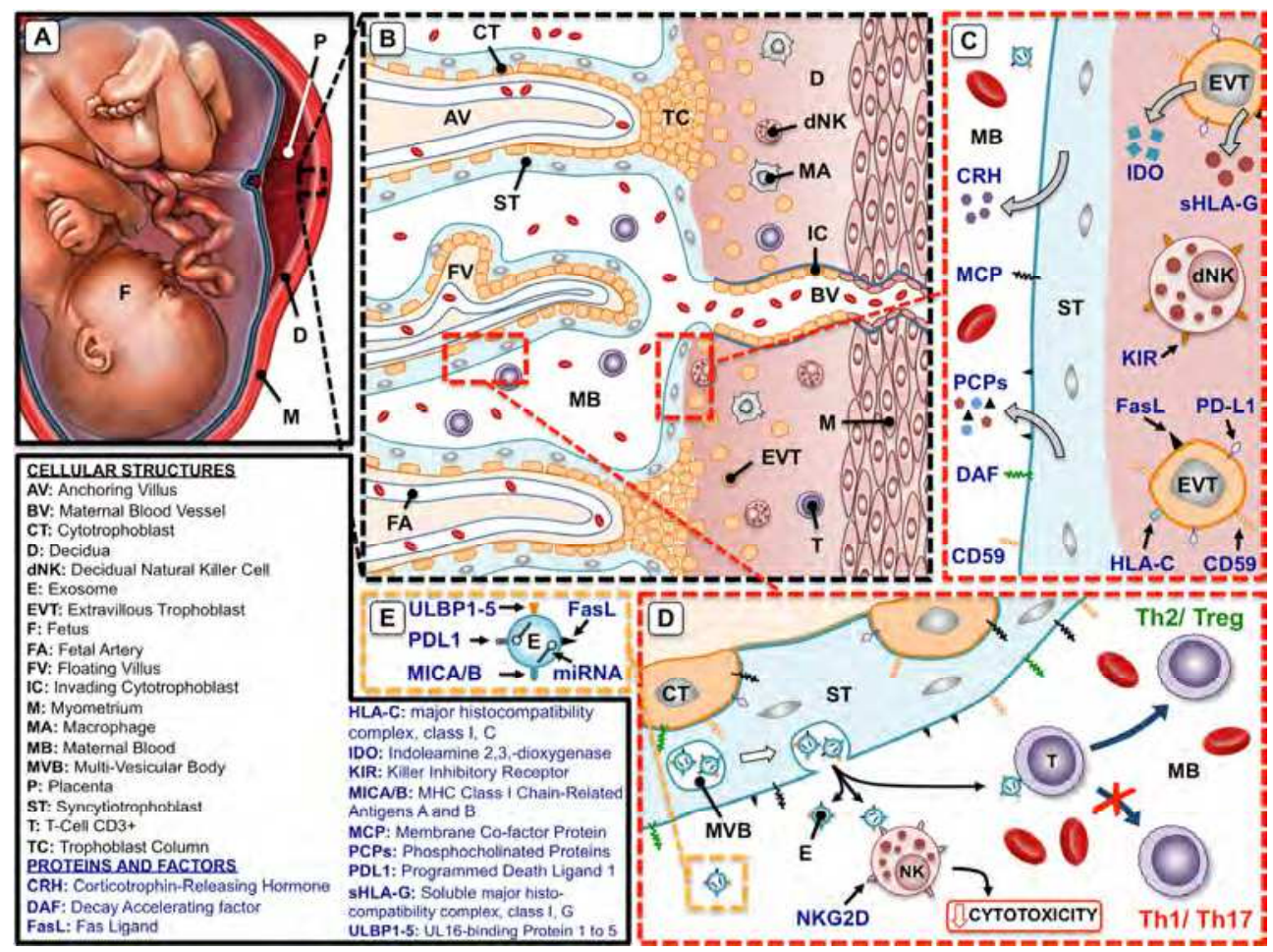

Fig. 1. Some of the mechanisms operating at the feto maternal interface that contribute to the immune tolerance towards fetal antigens. The immune regulatory processes operating at the level of the maternal fetal interface are highly dynamic and invoke multiple and sometimes redundant mechanisms and/or factors to reduce the likelihood of maternal immune rejection. Together with this redundancy, it is widely accepted that fetal factors drive changes in maternal immune responses and that both the fetus and the mother actively contribute to the successful pregnancy. A) General overview of the anatomical relationship between the feto placental unit within the uterus. B) Humans have a haemochorial placenta characterized by a high level of infiltration of maternal tissues by extravillous trophoblast cells and the release of maternal blood into the intervillous space. In this form of placentation the mother and the fetus are separated by a villous trophoblast layer which consists of an outer syncytiotrophoblast layer and an inner cytotrophoblast layer. The syncytiotrophoblast is formed by the fusion of the underlying mononuclear cytotrophoblast layer to form a multinucleated syncytium. C) Numerous factors are expressed at the maternal fetal interface which can regulate the maternal immune system to tolerate the presence of fetal antigens. These factors can be carried by either syncytiotrophoblast or extravillous trophoblast or may even be produced by maternal immune cell subtypes present in the decidua. Multiple strategies are used by trophoblast cells to avoid maternal immune cells and antibody-mediated cell destruction, including altered HLA expression (HLA-G, HLA-C), synthesis of immunosuppressive molecules such as FasL, PDL1, IDO, and expression of high levels of complement regulatory proteins (DAF, $\mathrm{MCP}, \mathrm{CD} 59)$ that protect the extraembryonic tissues from maternal anti-paternal cytotoxic 
antibodies. Uterine changes during pregnancy also help contribute to maternal immune adaptation, including alterations in the relative proportions, phenotype, and functions of leukocyte subpopulations, induction of immunosuppressive molecules (progesterone, prostaglandins), and changes in cytokine profiles across gestation. D) More recently, studies detailing the secretion of immunosuppressive exosomes by trophoblast cells have led to the hypothesis that placental derived exosomes may play an important role in the shift from a Th1/Th17 immune response, which promotes rejection, toward a Th2/Treg cell response that promotes tolerance as it inhibits Natural Cell Killer cytotoxicity against trophoblast cells. E) A number of immunosuppressive molecules have been documented as being carried by placental exosomes, including FasL, PDL1, MHC molecules, NKG2D ligands as well as miRNAs that may modulate the immune response.

The knowledge gained from research into the mechanisms of maternal immune tolerance can lead to a greater understanding of the processes vital to the establishment and maintenance of tolerance. These findings can not only contribute to developing therapeutic strategies to treat pregnancy immune related disorders such as preeclampsia or some infertilities but also to develop interventions to address malignancies in cancer and also to improve transplantation success rates.

\section{References}

Aluvihare, V. R., Kallikourdis, M. and Betz, A. G. (2004). Regulatory T cells mediate maternal tolerance to the fetus. Nat Immunol, Vol. 5, No. 3, pp. 266-71.

Arck, P. C., Ferrick, D. A., Steele-Norwood, D., Egan, P. J., Croitoru, K., Carding, S. R., Dietl, J. and Clark, D. A. (1999). Murine T cell determination of pregnancy outcome. Cell Immunol, Vol. 196, No. 2, pp. 71-9.

Ayatollahi, M., Geramizadeh, B., Yazdani, M. and Azarpira, N. (2007). Effect of the immunoregulatory cytokines on successful pregnancy depends upon the control of graft rejection mechanisms. Transplant Proc, Vol. 39, No. 1, pp. 244-5.

Baban, B., Chandler, P., McCool, D., Marshall, B., Munn, D. H. and Mellor, A. L. (2004). Indoleamine 2,3-dioxygenase expression is restricted to fetal trophoblast giant cells during murine gestation and is maternal genome specific. J Reprod Immunol, Vol. 61, No. 2, pp. 67-77.

Bainbridge, D. R. (2000). Evolution of mammalian pregnancy in the presence of the maternal immune system. Rev Reprod, Vol. 5, No. 2, pp. 67-74.

Beagley, K. W. and Gockel, C. M. (2003). Regulation of innate and adaptive immunity by the female sex hormones oestradiol and progesterone. FEMS Immunol Med Microbiol, Vol. 38, No. 1, pp. 13-22.

Billingham, R. E. (1964). Transplantation Immunity and the Maternal-Fetal Relationship. N Engl J Med, Vol. 270, No. pp. 667-72.

Billington, W. D. (1992). Transfer of antigens and antibodies between mother and fetus. In Immunological Obstetrics eds. C. B. Coulam W. P. Faulk and J. McIntyre), pp. 290304. New York: W.W. Norton and Co.

Billington, W. D. (2003). The immunological problem of pregnancy: 50 years with the hope of progress. A tribute to Peter Medawar. J Reprod Immunol, Vol. 60, No. 1, pp. 1-11.

Blaise, S., de Parseval, N., Benit, L. and Heidmann, T. (2003). Genomewide screening for fusogenic human endogenous retrovirus envelopes identifies syncytin 2, a gene 
conserved on primate evolution. Proc Natl Acad Sci U S A, Vol. 100, No. 22, pp. 13013-8.

Blaise, S., Mangeney, M. and Heidmann, T. (2001). The envelope of Mason-Pfizer monkey virus has immunosuppressive properties. J Gen Virol, Vol. 82, No. Pt 7, pp. 1597600.

Blank, C., Gajewski, T. F. and Mackensen, A. (2005). Interaction of PD-L1 on tumor cells with PD-1 on tumor-specific $\mathrm{T}$ cells as a mechanism of immune evasion: implications for tumor immunotherapy. Cancer Immunol Immunother, Vol. 54, No. 4, pp. 307-14.

Blond, J. L., Beseme, F., Duret, L., Bouton, O., Bedin, F., Perron, H., Mandrand, B. and Mallet, F. (1999). Molecular characterization and placental expression of HERV-W, a new human endogenous retrovirus family. J Virol, Vol. 73, No. 2, pp. 1175-85.

Blond, J. L., Lavillette, D., Cheynet, V., Bouton, O., Oriol, G., Chapel-Fernandes, S., Mandrand, B., Mallet, F. and Cosset, F. L. (2000). An envelope glycoprotein of the human endogenous retrovirus HERV-W is expressed in the human placenta and fuses cells expressing the type D mammalian retrovirus receptor. J Virol, Vol. 74, No. 7, pp. 3321-9.

Carosella, E. D., Moreau, P., Lemaoult, J. and Rouas-Freiss, N. (2008). HLA-G: from biology to clinical benefits. Trends Immunol, Vol. 29, No. 3, pp. 125-32.

Chaouat, G. (2007). The Th1/Th2 paradigm: still important in pregnancy? Semin Immunopathol, Vol. 29, No. 2, pp. 95-113.

Chaouat, G., Assal Meliani, A., Martal, J., Raghupathy, R., Elliott, J. F., Mosmann, T. and Wegmann, T. G. (1995). IL-10 prevents naturally occurring fetal loss in the CBA $x$ DBA/ 2 mating combination, and local defect in IL-10 production in this abortionprone combination is corrected by in vivo injection of IFN-tau. J Immunol, Vol. 154, No. 9, pp. 4261-8.

Chaouat, G., Ledee-Bataille, N., Zourbas, S., Ostojic, S., Dubanchet, S., Martal, J. and Frydman, R. (2003). Cytokines, implantation and early abortion: re-examining the Th1/Th2 paradigm leads to question the single pathway, single therapy concept. Am J Reprod Immunol, Vol. 50, No. 3, pp. 177-86.

Chaouat, G., Menu, E., Clark, D. A., Dy, M., Minkowski, M. and Wegmann, T. G. (1990). Control of fetal survival in CBA x DBA/2 mice by lymphokine therapy. J Reprod Fertil, Vol. 89, No. 2, pp. 447-58.

Chen, Z. M., O'Shaughnessy, M. J., Gramaglia, I., Panoskaltsis-Mortari, A., Murphy, W. J., Narula, S., Roncarolo, M. G. and Blazar, B. R. (2003). IL-10 and TGF-beta induce alloreactive CD4+CD25- T cells to acquire regulatory cell function. Blood, Vol. 101, No. 12, pp. 5076-83.

Cianciolo, G. J., Bogerd, H. P., Kipnis, R. J., Copeland, T. D., Oroszlan, S. and Snyderman, R. (1985). Inhibition of lymphocyte proliferation by a synthetic peptide homologous to envelope proteins of human and animal retroviruses. Trans Assoc Am Physicians, Vol. 98, No. pp. 30-41.

Clark, D. A., Fernandes, J. and Banwatt, D. (2008). Prevention of spontaneous abortion in the CBA $\times$ DBA/ 2 mouse model by intravaginal TGF-beta and local recruitment of CD4+8+ FOXP3+ cells. Am J Reprod Immunol, Vol. 59, No. 6, pp. 525-34.

Comiskey, M., Goldstein, C. Y., De Fazio, S. R., Mammolenti, M., Newmark, J. A. and Warner, C. M. (2003). Evidence that HLA-G is the functional homolog of mouse Qa-2, the Ped gene product. Hum Immunol, Vol. 64, No. 11, pp. 999-1004. 
Danilova, N. (2006). The evolution of immune mechanisms. J Exp Zool B Mol Dev Evol, Vol. 306, No. 6, pp. 496-520.

de Moraes-Pinto, M. I., Vince, G. S., Flanagan, B. F., Hart, C. A. and Johnson, P. M. (1997). Localization of IL-4 and IL-4 receptors in the human term placenta, decidua and amniochorionic membranes. Immunology, Vol. 90, No. 1, pp. 87-94.

Dupressoir, A., Marceau, G., Vernochet, C., Benit, L., Kanellopoulos, C., Sapin, V. and Heidmann, T. (2005). Syncytin-A and syncytin-B, two fusogenic placenta-specific murine envelope genes of retroviral origin conserved in Muridae. Proc Natl Acad Sci U S A, Vol. 102, No. 3, pp. 725-30.

Elbe-Burger, A., Mommaas, A. M., Prieschl, E. E., Fiebiger, E., Baumruker, T. and Stingl, G. (2000). Major histocompatibility complex class II- fetal skin dendritic cells are potent accessory cells of polyclonal T-cell responses. Immunology, Vol. 101, No. 2, pp. 242-53.

Faulk, W. P. and Temple, A. (1976). Distribution of beta2 microglobulin and HLA in chorionic villi of human placentae. Nature, Vol. 262, No. 5571, pp. 799-802.

Foulds, L. M., Boysen, R. I., Crane, M., Yang, Y., Muir, J. A., Smith, A. I., de Kretser, D. M., Hearn, M. T. and Hedger, M. P. (2008). Molecular identification of lysoglycerophosphocholines as endogenous immunosuppressives in bovine and rat gonadal fluids. Biol Reprod, Vol. 79, No. 3, pp. 525-36.

Frangsmyr, L., Baranov, V., Nagaeva, O., Stendahl, U., Kjellberg, L. and Mincheva-Nilsson, L. (2005). Cytoplasmic microvesicular form of Fas ligand in human early placenta: switching the tissue immune privilege hypothesis from cellular to vesicular level. Mol Hum Reprod, Vol. 11, No. 1, pp. 35-41.

Girardi, G. (2008). Complement inhibition keeps mothers calm and avoids fetal rejection. Immunol Invest, Vol. 37, No. 5, pp. 645-59.

Girardi, G., Bulla, R., Salmon, J. E. and Tedesco, F. (2006). The complement system in the pathophysiology of pregnancy. Mol Immunol, Vol. 43, No. 1-2, pp. 68-77.

Goodfellow, P. N., Barnstable, C. J., Bodmer, W. F., Snary, D. and Crumpton, M. J. (1976). Expression of HLA system antigens on placenta. Transplantation, Vol. 22, No. 6, pp. 595-603.

Gorivodsky, M., Torchinsky, A., Zemliak, I., Savion, S., Fein, A. and Toder, V. (1999). TGF beta 2 mRNA expression and pregnancy failure in mice. Am J Reprod Immunol, Vol. 42, No. 2, pp. 124-33.

Grammatopoulos, D. K. (2008). Placental corticotrophin-releasing hormone and its receptors in human pregnancy and labour: still a scientific enigma. J Neuroendocrinol, Vol. 20, No. 4, pp. 432-8.

Griffith, T. S., Brunner, T., Fletcher, S. M., Green, D. R. and Ferguson, T. A. (1995). Fas ligand-induced apoptosis as a mechanism of immune privilege. Science, Vol. 270, No. 5239, pp. 1189-92.

Grohmann, U., Fallarino, F. and Puccetti, P. (2003). Tolerance, DCs and tryptophan: much ado about IDO. Trends Immunol, Vol. 24, No. 5, pp. 242-8.

Groux, H., O'Garra, A., Bigler, M., Rouleau, M., Antonenko, S., de Vries, J. E. and Roncarolo, M. G. (1997). A CD4+ T-cell subset inhibits antigen-specific T-cell responses and prevents colitis. Nature, Vol. 389, No. 6652, pp. 737-42.

Guerin, L. R., Prins, J. R. and Robertson, S. A. (2009). Regulatory T-cells and immune tolerance in pregnancy: a new target for infertility treatment? Hum Reprod Update, Vol. 15, No. 5, pp. 517-35. 
Guleria, I., Khosroshahi, A., Ansari, M. J., Habicht, A., Azuma, M., Yagita, H., Noelle, R. J., Coyle, A., Mellor, A. L., Khoury, S. J. et al. (2005). A critical role for the programmed death ligand 1 in fetomaternal tolerance. J Exp Med, Vol. 202, No. 2, pp. 231-7.

Hansen, P. J., Bazer, F. W. and Segerson, E. C., Jr. (1986). Skin graft survival in the uterine lumen of ewes treated with progesterone. Am J Reprod Immunol Microbiol, Vol. 12, No. 2, pp. 48-54.

Haraguchi, S., Good, R. A., Cianciolo, G. J., Engelman, R. W. and Day, N. K. (1997). Immunosuppressive retroviral peptides: immunopathological implications for immunosuppressive influences of retroviral infections. J Leukoc Biol, Vol. 61, No. 6, pp. 654-66.

Haraguchi, S., Good, R. A. and Day-Good, N. K. (2008). A potent immunosuppressive retroviral peptide: cytokine patterns and signaling pathways. Immunol Res, Vol. 41, No. 1, pp. 46-55.

Harnett, W. and Harnett, M. M. (1993). Inhibition of murine B cell proliferation and downregulation of protein kinase $\mathrm{C}$ levels by a phosphorylcholine-containing filarial excretory-secretory product. J Immunol, Vol. 151, No. 9, pp. 4829-37.

Harris, J. R. (1991). The evolution of placental mammals. FEBS Lett, Vol. 295, No. 1-3, pp. 3-4.

Heidmann, O., Vernochet, C., Dupressoir, A. and Heidmann, T. (2009). Identification of an endogenous retroviral envelope gene with fusogenic activity and placenta-specific expression in the rabbit : a new "syncytin" in a third order of mammals. Retrovirology, Vol. 6, No. 1, pp. 107.

Heikkinen, J., Mottonen, M., Alanen, A. and Lassila, O. (2004). Phenotypic characterization of regulatory $\mathrm{T}$ cells in the human decidua. Clin Exp Immunol, Vol. 136, No. 2, pp. 373-8.

Hill, J. A., Polgar, K. and Anderson, D. J. (1995). T-helper 1-type immunity to trophoblast in women with recurrent spontaneous abortion. Jama, Vol. 273, No. 24, pp. 1933-6.

Holmes, C. H., Simpson, K. L., Okada, H., Okada, N., Wainwright, S. D., Purcell, D. F. and Houlihan, J. M. (1992). Complement regulatory proteins at the feto-maternal interface during human placental development: distribution of CD59 by comparison with membrane cofactor protein (CD46) and decay accelerating factor (CD55). Eur J Immunol, Vol. 22, No. 6, pp. 1579-85.

Hori, J., Wang, M., Miyashita, M., Tanemoto, K., Takahashi, H., Takemori, T., Okumura, K., Yagita, H. and Azuma, M. (2006). B7-H1-induced apoptosis as a mechanism of immune privilege of corneal allografts. J Immunol, Vol. 177, No. 9, pp. 5928-35.

Horwitz, D. A., Zheng, S. G. and Gray, J. D. (2003). The role of the combination of IL-2 and TGF-beta or IL-10 in the generation and function of CD4+ CD25+ and CD8+ regulatory T cell subsets. J Leukoc Biol, Vol. 74, No. 4, pp. 471-8.

Horwitz, D. A., Zheng, S. G. and Gray, J. D. (2008). Natural and TGF-beta-induced Foxp3(+)CD4(+) CD25(+) regulatory $\mathrm{T}$ cells are not mirror images of each other. Trends Immunol, Vol. 29, No. 9, pp. 429-35.

Hoskin, D. W. and Murgita, R. A. (1989). Specific maternal anti-fetal lymphoproliferative responses and their regulation by natural immunosuppressive factors. Clin Exp Immunol, Vol. 76, No. 2, pp. 262-7.

Houston, A. and O'Connell, J. (2004). The Fas signalling pathway and its role in the pathogenesis of cancer. Curr Opin Pharmacol, Vol. 4, No. 4, pp. 321-6. 
Hsi, B. L., Hunt, J. S. and Atkinson, J. P. (1991). Differential expression of complement regulatory proteins on subpopulations of human trophoblast cells. J Reprod Immunol, Vol. 19, No. 3, pp. 209-23.

Hunt, J. S. (1989). Cytokine networks in the uteroplacental unit: macrophages as pivotal regulatory cells. J Reprod Immunol, Vol. 16, No. 1, pp. 1-17.

Hunt, J. S. (2006). Stranger in a strange land. Immunol Rev, Vol. 213, No. pp. 36-47.

Hunt, J. S., Fishback, J. L., Andrews, G. K. and Wood, G. W. (1988). Expression of class I HLA genes by trophoblast cells. Analysis by in situ hybridization. J Immunol, Vol. 140, No. 4, pp. 1293-9.

Hunt, J. S. and Langat, D. L. (2009). HLA-G: a human pregnancy-related immunomodulator. Curr Opin Pharmacol, Vol. 9, No. 4, pp. 462-9.

Hunt, J. S., Petroff, M. G., McIntire, R. H. and Ober, C. (2005). HLA-G and immune tolerance in pregnancy. Faseb J, Vol. 19, No. 7, pp. 681-93.

Hunt, J. S., Vassmer, D., Ferguson, T. A. and Miller, L. (1997). Fas ligand is positioned in mouse uterus and placenta to prevent trafficking of activated leukocytes between the mother and the conceptus. J Immunol, Vol. 158, No. 9, pp. 4122-8.

Ishida, Y., Agata, Y., Shibahara, K. and Honjo, T. (1992). Induced expression of PD-1, a novel member of the immunoglobulin gene superfamily, upon programmed cell death. Embo J, Vol. 11, No. 11, pp. 3887-95.

Jasper, M. J., Tremellen, K. P. and Robertson, S. A. (2006). Primary unexplained infertility is associated with reduced expression of the T-regulatory cell transcription factor Foxp3 in endometrial tissue. Mol Hum Reprod, Vol. 12, No. 5, pp. 301-8.

Kalantaridou, S. N., Zoumakis, E., Makrigiannakis, A., Godoy, H. and Chrousos, G. P. (2007). The role of corticotropin-releasing hormone in blastocyst implantation and early fetal immunotolerance. Horm Metab Res, Vol. 39, No. 6, pp. 474-7.

Kingsley, C. I., Karim, M., Bushell, A. R. and Wood, K. J. (2002). CD25+CD4+ regulatory T cells prevent graft rejection: CTLA-4- and IL-10-dependent immunoregulation of alloresponses. J Immunol, Vol. 168, No. 3, pp. 1080-6.

Kobe, B., Center, R. J., Kemp, B. E. and Poumbourios, P. (1999). Crystal structure of human T cell leukemia virus type 1 gp21 ectodomain crystallized as a maltose-binding protein chimera reveals structural evolution of retroviral transmembrane proteins. Proc Natl Acad Sci U S A, Vol. 96, No. 8, pp. 4319-24.

Koshi, K., Ushizawa, K., Kizaki, K., Takahashi, T. and Hashizume, K. (2011). Expression of endogenous retrovirus-like transcripts in bovine trophoblastic cells. Placenta, Vol. 32, No. 7, pp. 493-9.

Kozma, N., Halasz, M., Palkovics, T. and Szekeres-Bartho, J. (2006). The progesteroneinduced blocking factor modulates the balance of PKC and intracellular Ca. Am J Reprod Immunol, Vol. 55, No. 2, pp. 122-9.

Kuby, J. (1997). Major Histocompatibility Complex. In Immunology (ed. D. Allen), pp. 223248: W.H. Freeman and Company.

Kudaka, W., Oda, T., Jinno, Y., Yoshimi, N. and Aoki, Y. (2007). Cellular Localization of Placenta-Specific Human Endogenous Retrovirus (HERV) Transcripts and their Possible Implication in Pregnancy-Induced Hypertension. Placenta, Vol. 29, No. 3, pp. 282-289.

Kudo, Y. and Boyd, C. A. (2000). Human placental indoleamine 2,3-dioxygenase: cellular localization and characterization of an enzyme preventing fetal rejection. Biochim Biophys Acta, Vol. 1500, No. 1, pp. 119-24. 
Kudo, Y. and Boyd, C. A. (2001). The role of L-tryptophan transport in L-tryptophan degradation by indoleamine 2,3-dioxygenase in human placental explants. J Physiol, Vol. 531, No. Pt 2, pp. 417-23.

Kudo, Y., Boyd, C. A., Sargent, I. L. and Redman, C. W. (2001). Tryptophan degradation by human placental indoleamine 2,3-dioxygenase regulates lymphocyte proliferation. J Physiol, Vol. 535, No. Pt 1, pp. 207-15.

Kyurkchiev, D., Ivanova-Todorova, E. and Kyurkchiev, S. D. (2010). New target cells of the immunomodulatory effects of progesterone. Reprod Biomed Online, Vol. 21, No. 3, pp. 304-11.

Lal, R. B., Kumaraswami, V., Steel, C. and Nutman, T. B. (1990). Phosphocholine-containing antigens of Brugia malayi nonspecifically suppress lymphocyte function. Am J Trop Med Hyg, Vol. 42, No. 1, pp. 56-64.

Larsen, M. H. and Hviid, T. V. (2009). Human leukocyte antigen-G polymorphism in relation to expression, function, and disease. Hum Immunol, Vol. 70, No. 12, pp. 1026-34.

Le Bouteiller, P. (1996). HLA Class I Genes and Products. In HLA and the maternal-fetal relationship (ed. J. S. Hunt), pp. 51-85. Heidelberg: R.G. Landes company.

Lee, H. O. and Ferguson, T. A. (2003). Biology of FasL. Cytokine Growth Factor Rev, Vol. 14, No. 3-4, pp. 325-35.

Lee, J. H., Ulrich, B., Cho, J., Park, J. and Kim, C. H. (2011). Progesterone promotes differentiation of human cord blood fetal $\mathrm{T}$ cells into $\mathrm{T}$ regulatory cells but suppresses their differentiation into th17 cells. J Immunol, Vol. 187, No. 4, pp. 177887.

Lovell, T. M., Woods, R. J., Butlin, D. J., Brayley, K. J., Manyonda, I. T., Jarvis, J., Howell, S. and Lowry, P. J. (2007). Identification of a novel mammalian post-translational modification, phosphocholine, on placental secretory polypeptides. J Mol Endocrinol, Vol. 39, No. 3, pp. 189-98.

Lowry, P. J. (2008). The placenta is simply a neuroendocrine parasite. J Neuroendocrinol, Vol. 20, No. 6, pp. 700-4.

Madeja, Z., Yadi, H., Apps, R., Boulenouar, S., Roper, S. J., Gardner, L., Moffett, A., Colucci, F. and Hemberger, M. (2011). Paternal MHC expression on mouse trophoblast affects uterine vascularization and fetal growth. Proc Natl Acad Sci U S A, Vol. 108, No. 10, pp. 4012-7.

Makrigiannakis, A., Zoumakis, E., Kalantaridou, S. and Chrousos, G. (2004). Endometrial and placental CRH as regulators of human embryo implantation. J Reprod Immunol, Vol. 62, No. 1-2, pp. 53-9.

Makrigiannakis, A., Zoumakis, E., Kalantaridou, S., Coutifaris, C., Margioris, A. N., Coukos, G., Rice, K. C., Gravanis, A. and Chrousos, G. P. (2001). Corticotropin-releasing hormone promotes blastocyst implantation and early maternal tolerance. Nat Immunol, Vol. 2, No. 11, pp. 1018-24.

Malassine, A., Frendo, J. L., Blaise, S., Handschuh, K., Gerbaud, P., Tsatsaris, V., Heidmann, T. and Evain-Brion, D. (2008). Human endogenous retrovirus-FRD envelope protein (syncytin 2) expression in normal and trisomy 21-affected placenta. Retrovirology, Vol. 5, No. 1, pp. 6.

Mangeney, M., de Parseval, N., Thomas, G. and Heidmann, T. (2001). The full-length envelope of an HERV-H human endogenous retrovirus has immunosuppressive properties. J Gen Virol, Vol. 82, No. Pt 10, pp. 2515-8. 
Mangeney, M. and Heidmann, T. (1998). Tumor cells expressing a retroviral envelope escape immune rejection in vivo. Proc Natl Acad Sci U S A, Vol. 95, No. 25, pp. 14920-5.

Mangeney, M., Renard, M., Schlecht-Louf, G., Bouallaga, I., Heidmann, O., Letzelter, C., Richaud, A., Ducos, B. and Heidmann, T. (2007). Placental syncytins: Genetic disjunction between the fusogenic and immunosuppressive activity of retroviral envelope proteins. Proc Natl Acad Sci U S A, Vol. 104, No. 51, pp. 20534-9.

Mao, G., Wang, J., Kang, Y., Tai, P., Wen, J., Zou, Q., Li, G., Ouyang, H., Xia, G. and Wang, B. (2010). Progesterone increases systemic and local uterine proportions of CD4+CD25+ Treg cells during midterm pregnancy in mice. Endocrinology, Vol. 151, No. 11, pp. 5477-88.

Marzi, M., Vigano, A., Trabattoni, D., Villa, M. L., Salvaggio, A., Clerici, E. and Clerici, M. (1996). Characterization of type 1 and type 2 cytokine production profile in physiologic and pathologic human pregnancy. Clin Exp Immunol, Vol. 106, No. 1, pp. 127-33.

McLean, M. and Smith, R. (2001). Corticotrophin-releasing hormone and human parturition. Reproduction, Vol. 121, No. 4, pp. 493-501.

Medawar, P. B. (1953). Some immunological and endocrinological problems raised by the evolution of viviparity in vertebrates. Symp. Soc. Exp. Biol., Vol. 44, No. pp. 320-338.

Mellor, A. L. and Munn, D. H. (1999). Tryptophan catabolism and T-cell tolerance: immunosuppression by starvation? Immunol Today, Vol. 20, No. 10, pp. 469-73.

Mi, S., Lee, X., Li, X., Veldman, G. M., Finnerty, H., Racie, L., LaVallie, E., Tang, X. Y., Edouard, P., Howes, S. et al. (2000). Syncytin is a captive retroviral envelope protein involved in human placental morphogenesis. Nature, Vol. 403, No. 6771, pp. 785-9.

Mincheva-Nilsson, L. and Baranov, V. (2010). The role of placental exosomes in reproduction. Am J Reprod Immunol, Vol. 63, No. 6, pp. 520-33.

Mjosberg, J., Berg, G., Ernerudh, J. and Ekerfelt, C. (2007). CD4+ CD25+ regulatory T cells in human pregnancy: development of a Treg-MLC-ELISPOT suppression assay and indications of paternal specific Tregs. Immunology, Vol. 120, No. 4, pp. 456-66.

Mjosberg, J., Svensson, J., Johansson, E., Hellstrom, L., Casas, R., Jenmalm, M. C., Boij, R., Matthiesen, L., Jonsson, J. I., Berg, G. et al. (2009). Systemic reduction of functionally suppressive CD4dimCD25highFoxp3+ Tregs in human second trimester pregnancy is induced by progesterone and 17beta-estradiol. J Immunol, Vol. 183, No. 1, pp. 759-69.

Morgan, B. P. and Holmes, C. H. (2000). Immunology of reproduction: protecting the placenta. Curr Biol, Vol. 10, No. 10, pp. R381-3.

Mosmann, T. R., Cherwinski, H., Bond, M. W., Giedlin, M. A. and Coffman, R. L. (1986). Two types of murine helper $\mathrm{T}$ cell clone. I. Definition according to profiles of lymphokine activities and secreted proteins. J Immunol, Vol. 136, No. 7, pp. 2348-57.

Mulley, W. R. and Nikolic-Paterson, D. J. (2008). Indoleamine 2,3-dioxygenase in transplantation. Nephrology (Carlton), Vol. 13, No. 3, pp. 204-11.

Munn, D. H. (2011). Indoleamine 2,3-dioxygenase, Tregs and Cancer. Curr Med Chem, Vol. 18, No. 15, pp. 2240-6.

Munn, D. H., Shafizadeh, E., Attwood, J. T., Bondarev, I., Pashine, A. and Mellor, A. L. (1999). Inhibition of T cell proliferation by macrophage tryptophan catabolism. J Exp Med, Vol. 189, No. 9, pp. 1363-72. 
Munn, D. H., Zhou, M., Attwood, J. T., Bondarev, I., Conway, S. J., Marshall, B., Brown, C. and Mellor, A. L. (1998). Prevention of allogeneic fetal rejection by tryptophan catabolism. Science, Vol. 281, No. 5380, pp. 1191-3.

Murphy, S. P., Choi, J. C. and Holtz, R. (2004). Regulation of major histocompatibility complex class II gene expression in trophoblast cells. Reprod Biol Endocrinol, Vol. 2, No. pp. 52.

Mwenda, J. M. (1994). Possible biological functions for the expression of endogenous retroviral gene products in human placental tissues. Cell Mol Biol (Noisy-le-grand), Vol. 40, No. 2, pp. 105-9.

Nagaeva, O., Jonsson, L. and Mincheva-Nilsson, L. (2002). Dominant IL-10 and TGF-beta mRNA expression in gammadeltaT cells of human early pregnancy decidua suggests immunoregulatory potential. Am J Reprod Immunol, Vol. 48, No. 1, pp. 917.

Nelson, J. L., Gillespie, K. M., Lambert, N. C., Stevens, A. M., Loubiere, L. S., Rutledge, J. C., Leisenring, W. M., Erickson, T. D., Yan, Z., Mullarkey, M. E. et al. (2007). Maternal microchimerism in peripheral blood in type 1 diabetes and pancreatic islet beta cell microchimerism. Proc Natl Acad Sci U S A, Vol. 104, No. 5, pp. 1637-42.

Nishimura, H. and Honjo, T. (2001). PD-1: an inhibitory immunoreceptor involved in peripheral tolerance. Trends Immunol, Vol. 22, No. 5, pp. 265-8.

Ober, C., Aldrich, C., Rosinsky, B., Robertson, A., Walker, M. A., Willadsen, S., Verp, M. S., Geraghty, D. E. and Hunt, J. S. (1998). HLA-G1 protein expression is not essential for fetal survival. Placenta, Vol. 19, No. 2-3, pp. 127-32.

Okahara, G., Matsubara, S., Oda, T., Sugimoto, J., Jinno, Y. and Kanaya, F. (2004). Expression analyses of human endogenous retroviruses (HERVs): tissue-specific and developmental stage-dependent expression of HERVs. Genomics, Vol. 84, No. 6, pp. 982-90.

Peterson, R. D., Hendrickson, R. and Good, R. A. (1963). Reduced Antibody Forming Capacity During the Incubation Period of Passage a Leukemia in C3h Mice. Proc Soc Exp Biol Med, Vol. 114, No. pp. 517-20.

Petraglia, F., Florio, P., Nappi, C. and Genazzani, A. R. (1996). Peptide signaling in human placenta and membranes: autocrine, paracrine, and endocrine mechanisms. Endocr Rev, Vol. 17, No. 2, pp. 156-86.

Petroff, M. G., Chen, L., Phillips, T. A., Azzola, D., Sedlmayr, P. and Hunt, J. S. (2003). B7 family molecules are favorably positioned at the human maternal-fetal interface. Biol Reprod, Vol. 68, No. 5, pp. 1496-504.

Petroff, M. G., Kharatyan, E., Torry, D. S. and Holets, L. (2005). The immunomodulatory proteins B7-DC, B7-H2, and B7-H3 are differentially expressed across gestation in the human placenta. Am J Pathol, Vol. 167, No. 2, pp. 465-73.

Poppa, G., Simmons, R. L., David, D. S. and Russell, P. S. (1964). The Uterus as a Recipient Site for Parathyroid Homotransplantation. Transplantation, Vol. 2, No. pp. 496-502.

Power, L. L., Popplewell, E. J., Holloway, J. A., Diaper, N. D., Warner, J. O. and Jones, C. A. (2002). Immunoregulatory molecules during pregnancy and at birth. J Reprod Immunol, Vol. 56, No. 1-2, pp. 19-28.

Prokunina, L., Castillejo-Lopez, C., Oberg, F., Gunnarsson, I., Berg, L., Magnusson, V., Brookes, A. J., Tentler, D., Kristjansdottir, H., Grondal, G. et al. (2002). A regulatory polymorphism in PDCD1 is associated with susceptibility to systemic lupus erythematosus in humans. Nat Genet, Vol. 32, No. 4, pp. 666-9. 
Raghupathy, R. (1997). Th1-type immunity is incompatible with successful pregnancy. Immunol Today, Vol. 18, No. 10, pp. 478-82.

Raghupathy, R. (2001). Pregnancy: success and failure within the Th1/Th2/Th3 paradigm. Semin Immunol, Vol. 13, No. 4, pp. 219-27.

Redman, C. W., McMichael, A. J., Stirrat, G. M., Sunderland, C. A. and Ting, A. (1984). Class 1 major histocompatibility complex antigens on human extra-villous trophoblast. Immunology, Vol. 52, No. 3, pp. 457-68.

Regateiro, F. S., Howie, D., Cobbold, S. P. and Waldmann, H. (2011). TGF-beta in transplantation tolerance. Curr Opin Immunol, Vol. No. pp.

Renard, M., Varela, P. F., Letzelter, C., Duquerroy, S., Rey, F. A. and Heidmann, T. (2005). Crystal structure of a pivotal domain of human syncytin-2, a 40 million years old endogenous retrovirus fusogenic envelope gene captured by primates. J Mol Biol, Vol. 352, No. 5, pp. 1029-34.

Robertson, S. A. (2010). Immune regulation of conception and embryo implantation-all about quality control? J Reprod Immunol, Vol. 85, No. 1, pp. 51-7.

Robertson, S. A., Guerin, L. R., Moldenhauer, L. M. and Hayball, J. D. (2009). Activating T regulatory cells for tolerance in early pregnancy - the contribution of seminal fluid. J Reprod Immunol, Vol. 83, No. 1-2, pp. 109-16.

Robertson, S. A., Ingman, W. V., O'Leary, S., Sharkey, D. J. and Tremellen, K. P. (2002). Transforming growth factor beta--a mediator of immune deviation in seminal plasma. J Reprod Immunol, Vol. 57, No. 1-2, pp. 109-28.

Rothstein, D. M. and Sayegh, M. H. (2003). T-cell costimulatory pathways in allograft rejection and tolerance. Immunol Rev, Vol. 196, No. pp. 85-108.

Ryan, F. P. (2004). Human endogenous retroviruses in health and disease: a symbiotic perspective. J R Soc Med, Vol. 97, No. 12, pp. 560-5.

Saito, S., Nakashima, A., Shima, T. and Ito, M. (2010). Th1/Th2/Th17 and regulatory T-cell paradigm in pregnancy. Am J Reprod Immunol, Vol. 63, No. 6, pp. 601-10.

Salmon, J. E., Heuser, C., Triebwasser, M., Liszewski, M. K., Kavanagh, D., Roumenina, L., Branch, D. W., Goodship, T., Fremeaux-Bacchi, V. and Atkinson, J. P. (2011). Mutations in complement regulatory proteins predispose to preeclampsia: a genetic analysis of the PROMISSE cohort. PLoS Med, Vol. 8, No. 3, pp. e1001013.

Sandrin, V., Muriaux, D., Darlix, J. L. and Cosset, F. L. (2004). Intracellular trafficking of Gag and Env proteins and their interactions modulate pseudotyping of retroviruses. $J$ Virol, Vol. 78, No. 13, pp. 7153-64.

Sasaki, Y., Darmochwal-Kolarz, D., Suzuki, D., Sakai, M., Ito, M., Shima, T., Shiozaki, A., Rolinski, J. and Saito, S. (2007). Proportion of peripheral blood and decidual CD4(+) CD25(bright) regulatory T cells in pre-eclampsia. Clin Exp Immunol, Vol. 149, No. 1, pp. 139-45.

Sasaki, Y., Sakai, M., Miyazaki, S., Higuma, S., Shiozaki, A. and Saito, S. (2004). Decidual and peripheral blood CD4+CD25+ regulatory $\mathrm{T}$ cells in early pregnancy subjects and spontaneous abortion cases. Mol Hum Reprod, Vol. 10, No. 5, pp. 347-53.

Schmidt-Weber, C. B. and Blaser, K. (2004). Regulation and role of transforming growth factor-beta in immune tolerance induction and inflammation. Curr Opin Immunol, Vol. 16, No. 6, pp. 709-16.

Siiteri, P. K., Febres, F., Clemens, L. E., Chang, R. J., Gondos, B. and Stites, D. (1977). Progesterone and maintenance of pregnancy: is progesterone nature's immunosuppressant? Ann N Y Acad Sci, Vol. 286, No. pp. 384-97. 
Somerset, D. A., Zheng, Y., Kilby, M. D., Sansom, D. M. and Drayson, M. T. (2004). Normal human pregnancy is associated with an elevation in the immune suppressive CD25+ CD4+ regulatory T-cell subset. Immunology, Vol. 112, No. 1, pp. 38-43.

Stein-Streilein, J. and Streilein, J. W. (2002). Anterior chamber associated immune deviation (ACAID): regulation, biological relevance, and implications for therapy. Int Rev Immunol, Vol. 21, No. 2-3, pp. 123-52.

Stites, D. P., Bugbee, S. and Siiteri, P. K. (1983). Differential actions of progesterone and cortisol on lymphocyte and monocyte interaction during lymphocyte activation-relevance to immunosuppression in pregnancy. J Reprod Immunol, Vol. 5, No. 4, pp. 215-28.

Szekeres-Bartho, J. (2002). Immunological relationship between the mother and the fetus. Int Rev Immunol, Vol. 21, No. 6, pp. 471-95.

Szekeres-Bartho, J., Faust, Z. and Varga, P. (1995). The expression of a progesterone-induced immunomodulatory protein in pregnancy lymphocytes. Am J Reprod Immunol, Vol. 34, No. 6, pp. 342-8.

Szekeres-Bartho, J., Szekeres, G., Debre, P., Autran, B. and Chaouat, G. (1990). Reactivity of lymphocytes to a progesterone receptor-specific monoclonal antibody. Cell Immunol, Vol. 125, No. 2, pp. 273-83.

Szekeres-Bartho, J. and Wegmann, T. G. (1996). A progesterone-dependent immunomodulatory protein alters the Th1/Th2 balance. J Reprod Immunol, Vol. 31, No. 1-2, pp. 81-95.

Szekeres-Bartho, J., Wilczynski, J. R., Basta, P. and Kalinka, J. (2008). Role of progesterone and progestin therapy in threatened abortion and preterm labour. Front Biosci, Vol. 13, No. pp. 1981-90.

Tafuri, A., Alferink, J., Moller, P., Hammerling, G. J. and Arnold, B. (1995). T cell awareness of paternal alloantigens during pregnancy. Science, Vol. 270, No. 5236, pp. 630-3.

Taglauer, E. S., Yankee, T. M. and Petroff, M. G. (2009). Maternal PD-1 regulates accumulation of fetal antigen-specific CD8+ T cells in pregnancy. J Reprod Immunol, Vol. 80, No. 1-2, pp. 12-21.

Tajima, A., Tanaka, T., Ebata, T., Takeda, K., Kawasaki, A., Kelly, J. M., Darcy, P. K., Vance, R. E., Raulet, D. H., Kinoshita, K. et al. (2003). Blastocyst MHC, a putative murine homologue of HLA-G, protects TAP-deficient tumor cells from natural killer cellmediated rejection in vivo. J Immunol, Vol. 171, No. 4, pp. 1715-21.

Taylor, D. D., Akyol, S. and Gercel-Taylor, C. (2006). Pregnancy-associated exosomes and their modulation of T cell signaling. J Immunol, Vol. 176, No. 3, pp. 1534-42.

Tedesco, F., Narchi, G., Radillo, O., Meri, S., Ferrone, S. and Betterle, C. (1993). Susceptibility of human trophoblast to killing by human complement and the role of the complement regulatory proteins. J Immunol, Vol. 151, No. 3, pp. 1562-70.

Thellin, O., Coumans, B., Zorzi, W., Igout, A. and Heinen, E. (2000). Tolerance to the foetoplacental 'graft': ten ways to support a child for nine months. Curr Opin Immunol, Vol. 12, No. 6, pp. 731-7.

Tristem, M. (2000). Identification and characterization of novel human endogenous retrovirus families by phylogenetic screening of the human genome mapping project database. J Virol, Vol. 74, No. 8, pp. 3715-30.

Trowsdale, J. and Betz, A. G. (2006). Mother's little helpers: mechanisms of maternal-fetal tolerance. Nat Immunol, Vol. 7, No. 3, pp. 241-6. 
Urnovitz, H. B. and Murphy, W. H. (1996). Human endogenous retroviruses: nature, occurrence, and clinical implications in human disease. Clin Microbiol Rev, Vol. 9, No. 1, pp. 72-99.

Vale, W., Spiess, J., Rivier, C. and Rivier, J. (1981). Characterization of a 41-residue ovine hypothalamic peptide that stimulates secretion of corticotropin and betaendorphin. Science, Vol. 213, No. 4514, pp. 1394-7.

Veenstra van Nieuwenhoven, A. L., Heineman, M. J. and Faas, M. M. (2003). The immunology of successful pregnancy. Hum Reprod Update, Vol. 9, No. 4, pp. 347-57.

Villarreal, L. P. (1997). On viruses, sex, and motherhood. J Virol, Vol. 71, No. 2, pp. 859-65.

Wang, L., Han, R. and Hancock, W. W. (2007). Programmed cell death 1 (PD-1) and its ligand PD-L1 are required for allograft tolerance. Eur J Immunol, Vol. 37, No. 10, pp. 2983-90.

Wasowska, B. A., Lee, C. Y., Halushka, M. K. and Baldwin, W. M., 3rd. (2007). New concepts of complement in allorecognition and graft rejection. Cell Immunol, Vol. 248, No. 1, pp. 18-30.

Wegmann, T. G., Lin, H., Guilbert, L. and Mosmann, T. R. (1993). Bidirectional cytokine interactions in the maternal-fetal relationship: is successful pregnancy a $\mathrm{TH} 2$ phenomenon? Immunol Today, Vol. 14, No. 7, pp. 353-6.

Xu, C., Mao, D., Holers, V. M., Palanca, B., Cheng, A. M. and Molina, H. (2000). A critical role for murine complement regulator crry in fetomaternal tolerance. Science, Vol. 287, No. 5452, pp. 498-501.

Yamamoto, S. and Hayaishi, O. (1967). Tryptophan pyrrolase of rabbit intestine. D- and Ltryptophan-cleaving enzyme or enzymes. J Biol Chem, Vol. 242, No. 22, pp. 5260-6.

Zenclussen, A. C., Gerlof, K., Zenclussen, M. L., Sollwedel, A., Bertoja, A. Z., Ritter, T., Kotsch, K., Leber, J. and Volk, H. D. (2005). Abnormal T-cell reactivity against paternal antigens in spontaneous abortion: adoptive transfer of pregnancy-induced CD4+CD25+ T regulatory cells prevents fetal rejection in a murine abortion model. Am J Pathol, Vol. 166, No. 3, pp. 811-22.

Zheng, S. G., Wang, J. and Horwitz, D. A. (2008). Cutting edge: Foxp3+CD4+CD25+ regulatory T cells induced by IL-2 and TGF-beta are resistant to Th17 conversion by IL-6. J Immunol, Vol. 180, No. 11, pp. 7112-6.

Zheng, S. G., Wang, J., Wang, P., Gray, J. D. and Horwitz, D. A. (2007). IL-2 is essential for TGF-beta to convert naive CD4+CD25- cells to CD25+Foxp3+ regulatory T cells and for expansion of these cells. J Immunol, Vol. 178, No. 4, pp. 2018-27.

Zipfel, P. F. and Skerka, C. (2009). Complement regulators and inhibitory proteins. Nat Rev Immunol, Vol. 9, No. 10, pp. 729-40. 


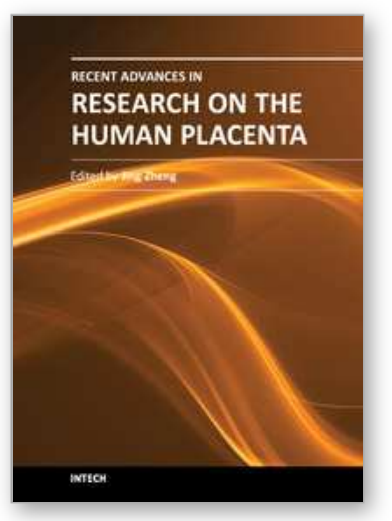

\author{
Recent Advances in Research on the Human Placenta \\ Edited by Dr. Jing Zheng
}

ISBN 978-953-51-0194-9

Hard cover, 428 pages

Publisher InTech

Published online 07, March, 2012

Published in print edition March, 2012

This book contains the total of 19 chapters, each of which is written by one or several experts in the corresponding field. The objective of this book is to provide a comprehensive and most updated overview of the human placenta, including current advances and future directions in the early detection, recognition, and management of placental abnormalities as well as the most common placental structure and functions, abnormalities, toxicology, infections, and pathologies. It also includes a highly controversial topic, therapeutic applications of the human placenta. A collection of articles presented by active investigators provides a clear update in the area of placental research for medical students, nurse practitioners, practicing clinicians, and biomedical researchers in the fields of obstetrics, pediatrics, family practice, genetics, and others who may be interested in human placentas.

\title{
How to reference
}

In order to correctly reference this scholarly work, feel free to copy and paste the following:

John E. Schjenken, Jorge M. Tolosa, Jonathan W. Paul, Vicki L. Clifton and Roger Smith (2012). Mechanisms of Maternal Immune Tolerance During Pregnancy, Recent Advances in Research on the Human Placenta, Dr. Jing Zheng (Ed.), ISBN: 978-953-51-0194-9, InTech, Available from: http://www.intechopen.com/books/recentadvances-in-research-on-the-human-placenta/mechanisms-of-maternal-immune-tolerance-during-pregnancy

\section{INTECH}

open science | open minds

\author{
InTech Europe \\ University Campus STeP Ri \\ Slavka Krautzeka 83/A \\ 51000 Rijeka, Croatia \\ Phone: +385 (51) 770447 \\ Fax: +385 (51) 686166 \\ www.intechopen.com
}

\author{
InTech China \\ Unit 405, Office Block, Hotel Equatorial Shanghai \\ No.65, Yan An Road (West), Shanghai, 200040, China \\ 中国上海市延安西路65号上海国际贵都大饭店办公楼 405 单元 \\ Phone: +86-21-62489820 \\ Fax: +86-21-62489821
}


(C) 2012 The Author(s). Licensee IntechOpen. This is an open access article distributed under the terms of the Creative Commons Attribution 3.0 License, which permits unrestricted use, distribution, and reproduction in any medium, provided the original work is properly cited. 